
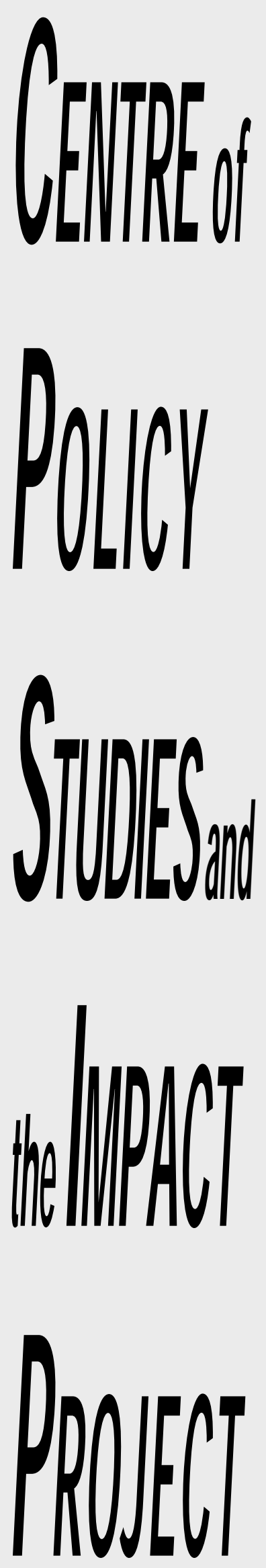

Eleventh Floor

Menzies Building

PO Box 11E, Monash University

Wellington Road

CLAYTON Vic 3800 AUSTRALIA

Telephone:

(03) 9905 2398, (03) 99055112

from overseas:

61399055112 or 61399052398

Fax:

(03) 99052426

61399052426

e-mail

web site

impact@vaxc.cc.monash.edu.au

http://www.monash.edu.au/policy/

\section{ABSORPTION CAPACITY, STRUCTURAL SIMILARITY AND EMBODIED TECHNOLOGY SPILOVERS IN A 'MACRO' MODEL: AN IMPLEMENTATION WITHIN THE GTAP FRAMEWORK by \\ Gouranga Gopal DAS}

and Alan A. POWEL

Centre of Policy Studies, Monash University

Preliminary Working Paper No. IP-77 December 2000

ISSN 10319034

ISBN 0732615283 


\begin{abstract}
In this paper, all technology transfers are embodied in trade flows within a three-region, one-traded-commodity version of the GTAP model. Exogenous Hicks-Neutral technical progress in one region can have uneven impacts on productivity elsewhere. Why? Destination regions' ability to harness new technology depends on their absorptive capacity and on the structural congruence of the source and destination. Together with trade volume, these two factors determine the recipient's spillover coefficient (which measures its success in capturing foreign technology). Armington competition between the outputs of the three economies and shifts in their terms of trade loom large in the general equilibrium adjustment.
\end{abstract}

JEL Classification: D58, F11, F41, O49. 


\section{CONTENTS}

$\begin{array}{ll}\text { Abstract } & \text { i }\end{array}$

1 Introduction 1

2 Theoretical Premise 2

2.1 Embodied Spillover Hypothesis 2

2.2 Production Technology and Spillover Function 4

2.2a Production Technology 4

2.2b Spillover Equation and Productivity Shock 5

3 The GTAP Database and Aggregation 8

3.1 Set Aggregation 8

3.2 Database Aggregation 9

3.3 Modification of Parameter Setting 9

4 GTAP Implementation $\quad 10$

4.1. Additional Equation 10

4.2. Closure and Shock 11

5 Analysis of Simulation Results 12

5.1. Macroeconomic Effects in Each Region 12

5.2 Inter-regional Competition Effects 16

5.2a Region-wide impact on sources of final demands 18

5.2b Regional Effect of investment allocation mechanism 23

5.2c Regional composition of International Trade 27

5.3 Sectoral Effects 32

5.3a Effects on Traded 'Stuff' Sector $\quad 32$

$5.3 \mathrm{~b}$ Effects on Non-traded Capital Goods Industry 33

$6 \quad$ Summary and Conclusion 35

$\begin{array}{ll}\text { References } & 37\end{array}$

$\begin{array}{ll}\text { Appendix } & 39\end{array}$

A.1 Set Modifications $\quad 39$

A.2 Appended Variables and Equations 41

A.3 Additional Parameters 45

A.4 Additional Coefficients 46

A.5 Encoded Computer Model and Software 47

A.6 Generating Aggregated Data Base 48

A.7 List of GTAP variables for current implementation 49

Table A1.1 Definition of Regions and of Commodities in 1x3 GTAP 40

Table A1.2 Modification for set definitions in TABLO File 41

Table A.7 List of GTAP variables in this implementation 50 


\section{LIST OF TABLES}

Table 3.1.1 List of sets and their elements in 1X3 GTAP 9

Table 3.3.1 Value of elasticities of substitution parameters 10

Table 4.1.1 Additional equation in the TABLO source file for $\begin{array}{ll}\text { technology spillover } & 11\end{array}$

Table 5.1.1. Simulated regional effects of technological change in the USA on selected macroeconomic variables

Table 5.1.2 Values of embodiment-index, spillover coefficient and capture-parameter

Table 5.2.1 Simulated regional effects on sources of final demand 17

Table 5.2.2 Simulated effects on nominal regional income 18

Table 5.2.3 Budget shares of each income use category and incdeflator 20

Table 5.2.4 Component-wise effects on pgdp 22

Table 5.2.5 Simulated effects on rate of returns and base-period values of some coefficients 23

Table 5.2.6a Base-case values of Gross Saving and Gross Investment 25

Table 5.2.6b Post-shock values of Gross Saving and Gross Investment 25

Table 5.2.7 Decomposition of percentage changes in regional TOT 29

Table 5.2.8 Simulated effects on bilateral export sales 32

Table 5.3.1 Simulated regional effects of technology shock on Stuff 33

Table 5.3.2 Simulated regional effects on capital goods industry 34

\section{FIGURES}

Figure 1 Production structure for region ' $r$ ' in the one-commodity, three-region version of GTAP 5

Figure 2 Flow chart for the transmission mechanism in the model 7

Figure 3 Flow chart showing the principal pathways behind the results 14 


\title{
ABSORPTION CAPACITY, STRUCTURAL SIMILARITY AND EMBODIED TECHNOLOGY SPILLOVERS IN A 'MACRO' MODEL: AN IMPLEMENTATION WITHIN THE GTAP FRAMEWORK
}

\author{
Gouranga Gopal DAS \\ and \\ Alan A. POWELL \\ Monash University
}

\section{Introduction}

We implement embodied knowledge spillovers in a highly aggregated version of the GTAP model - that is, a one-traded-commodity, three-region version of GTAP. ${ }^{1}$ At first sight it may seem surprising that a macro (onetraded commodity) model is used for this purpose. GTAP, like many CGE models, adopts Armington's (1969) treatment of commodity substitution, so that even if all regions produce the same generic commodity, the substitution elasticity between that commodity produced in region A and the "same" commodity produced in region $\mathrm{B}$, is not infinite. Thus, even in a onecommodity version of GTAP the 'Law of One Price' does not hold. Working at the one-commodity level has the advantage of concentrating on interregional competition in the goods market without having to deal with the large amount of detail entailed in keeping track also of inter-generic commodity substitution.

We aggregate the GTAP database to a one-commodity and threeregion (USA, EU, and ROW) database. The generic commodity that is traded internationally will be called Stuff. Each region produces one tradable good (its own type of Stuff) and one non-tradable (its own Capital Goods). It is necessary to include a non-tradable in each region because GTAP specifies that capital formation is supplied completely by a domestic industry which does not export. Note, however, that the domestic capital goods industry in any country merely assembles a bundle of traded goods (which include foreign tradables). Consumers absorb Stuff produced at home, as well as the two imported varieties.

We consider a Hicks-Neutral general total factor productivity (TFP) shock in the Stuff sector originating in one of the three regions, viz. the USA.

1 Various aggregations of the data are available, and in this paper a $3 \times 3$ aggregation of the database is the starting point from which a further aggregation is implemented to produce a three region macro model. 
Such a TFP shock is general output-augmenting by nature. Its impact on productivity in the destinations is studied via an embodiment index, an absorption capacity index, and a structural similarity index. Sections 2 and 3 describe the theoretical premise and the database corresponding to our aggregation respectively. Section 4 documents the GTAP implementation, the closure and the perturbation introduced into the system. Section 5 reports and explains the simulation results. Section 6 concludes.

\section{Theoretical Premise}

\subsection{Embodied Spillover Hypothesis ${ }^{2}$}

As has been argued elsewhere, growth and development of the LDCs depend not only on the extent and nature of the foreign technology which is available to them via participation in international trade in goods and services, but also on their capabilities for effectively absorbing the diffused state of the art. Current state-of-the-art technologies created by concerted research efforts are embodied in the commodities produced using the newly created ideas. The knowledge capital generated at the sources of inventions spills over to the destinations through bilateral trade linkages. This is the embodiment hypothesis: technical knowledge flows through traded goods. Note that the creation (as distinct from the transmission) of knowledge capital is beyond the scope of this paper.

The adaptability and local useability of the diffused technologies depends on the Absorptive Capacity (AC) [Cohen and Levinthal ${ }^{3}$ (1989, 1990)] of the destinations and the Structural Similarity (SS) [Hayami and Ruttan (1985)] between the trading nations. In the literature, the importance of SS has been discussed especially in the context of agriculture. Here in a single-sector model with one trading sector per region, this focus is not valid. However, the maximum potential for productivity enhancement attainable with a given stock of ideas can be achieved only if both AC and SS are high. ${ }^{4}$

2 Our approach is more modest than the approach by Eaton and Kortum (1994, 1996a \& b) [henceforth, EK], Grossman and Helpman (1991a \& b), Jones (1995). All of these dynamic general equilibrium models have considered the possible interlinkages between invention, technology diffusion, growth and productivity. Eaton and Kortum have developed an empirical dynamic general equilibrium model of technology-diffusion based on a "quality-ladder" approach in which, à la Grossman and Helpman (1991a), concerted R\&D effort improves the quality of the inputs over a production spectrum in continuum and this quality improvement embodied in the inputs is transmitted via the final products. Each input is produced with a conventional Cobb-Douglas, Constant Returns to Scale (CRTS) production technology where this quality-adjusted inputs are used to produce the final, traded product in a continuous analogue of the Cobb-Douglas, CRTS production function. Better quality inputs embodying the latest ideas always replace the 'state-of-the-art' currently in practice.

3 To the best of our knowledge, the role of such factors in assimilating the foreign technology was first emphasised in the literarure by Cohen and Levinthal. Based on their notion of absorption capacity and its importance, some authors like Keller (1997), Nelson (1990), to name a few, have extended the discussion initiated by them.

4 This aspect of "effective absorption" has not been studied by the authors cited above in footnote 2 . 
Van Meijl and Van Tongeren (MT) (1997) related productivity growth rates of countries through international trade linkages and associated embodied knowledge-spillovers. In their model, AC is constructed as a binary (source- and destination-specific) index of human-capital-induced absorption capacity of Country A vis-à-vis Country B. They also use a binary index for SS. It is based on the similarity of factor proportions in the two regions (but unlike AC, SS is symmetric). These two indexes conjointly determine the 'productive efficiency' parameter for effective assimilation of the technology by the recipient countries. ${ }^{5}$

Our model differs in several details. First, we restrict ourselves to a one-sector (tradable Stuff) technology for production. ${ }^{6}$ Stuff is produced in a world divided into three regions. Like "ectoplasm" in the one-sector neoclassical growth model, Stuff is easily transmutable from consumable to investment goods. Second, unlike MT where AC is a binary index involving both source and destination, we make the $\mathrm{AC}$ factor destination specific only. The SS factor retains its binary affix, though. Third, as will become evident below, we have modified MT's 'embodied spillover function'. We now justify the rationale behind the latter two modifications (the reason behind aggregation of goods into a macro model has been given in the Introduction).

It is argued that domestic useability of the transmitted foreign technology depends mainly on the recipient's capability to identify, procure and utilise the diffused technology. This simplification reflects our desire to keep the model simple by concentrating on first-order effects. It seems likely that if region $\mathrm{C}$ is good at absorbing technology from region $\mathrm{A}$, it will be equally good at absorbing technology from another region $\mathrm{B}$ which (from C's point of view) is structurally similar to A. Thus, the AC factor is made destination-specific only (unlike in MT where they carry both source and destination affixes).

The necessary modifications made in the basic spillover equation of MT are rationalised in the next section.

5 It is worthwhile to mention here that $\mathrm{AC}$ depends not only on Human Capital alone, but also on a constellation of factors such as Infrastructural Facilities, Learning Effects, and Own $R \& D$ in the recipients. However, we have not considered these factors while defining AC in our model. These are on our research agenda.

6 The second commodity produced in each region (Capital Goods, CGDS) is produced according to a 'technology' which merely assembles a bundle of Stuff from the three regions. However, it is a 'fictitious' industry. 


\subsection{Production Technology and Spillover Function}

\section{2a Production Technology}

The production technology tree in the GTAP model uses a nested production function. Here we specialize the notation for use with the one-tradedcommodity version.

At the top level, a composite output $\mathrm{Y}_{\mathrm{r}}$ is produced in region $\mathrm{r}$ with a Leontief fixed proportion technology using intermediate inputs $\mathrm{Q}_{\mathrm{r} \text {. }}$ and $\mathrm{a}$ primary input composite $\mathrm{Q}_{\mathrm{r} \text {. }}^{\mathrm{v}} \mathrm{Q}_{\mathrm{r} \text {. }}$ is intermediate input demand for Armington composite Stuff by any region $r$. Each $Q_{r}$ is produced in a CES production nest using domestic Stuff and a composite of foreign Stuff distinguished by country of origin (using the Armington assumption). Thus, we can write the CES production function for the intermediate input nest as

$$
\mathrm{Q}_{\mathrm{r}}=\mathrm{A}_{\mathrm{r}}\left\{\delta_{\mathrm{r}}^{\mathrm{D}}\left(\mathrm{Q}_{\mathrm{rr}}\right)^{-\beta_{\mathrm{r} .}}+\left(1-\delta_{\mathrm{r}}^{\mathrm{D}}\right)\left(\mathrm{Q}_{\mathrm{r}}^{\mathrm{F}}\right)^{-\beta_{\mathrm{r} .}}\right\}^{-1 / \beta_{\mathrm{r}}}
$$

where $r$ is the region using the domestically sourced tradable Stuff $Q_{r r}$ and the foreign inputs composite of Stuff $\mathrm{Q}_{\mathrm{r}}^{\mathrm{F}} \cdot \delta^{\mathrm{D}}$ is the distribution parameter (a positive fraction). $\beta_{\mathrm{r} .} \neq-1$ is the substitution parameter. The superscripts $\mathrm{D}$ and $\mathrm{F}$ are used to identify domestic and foreign components respectively. The substitution elasticity between domestic and foreign Stuff is $\left[1 /\left(1+\beta_{\mathrm{r} .}\right)\right]$.

For notational convenience, in $\mathrm{Q}_{\mathrm{rs}}$ the first subscript refers to the using region and the second one refers to the foreign source of Stuff. For example, let the three regions in our implementation be $A, B$ and $C$ so that $r, s \in\{A, B$, $\mathrm{C}\}$. Then, if $\mathrm{r}=\mathrm{C}$ is the using region, and $\mathrm{s}=\mathrm{B}$ or $\mathrm{A}, \mathrm{Q}_{\mathrm{rr}}=\mathrm{Q}_{\mathrm{CC}}$ is the domestically sourced Stuff in $C$ while $\mathrm{Q}_{\mathrm{CA}}$ and $\mathrm{Q}_{\mathrm{CB}}$ are Stuff imported by $\mathrm{C}$ from $B$ and A respectively.

$\mathrm{Q}_{\mathrm{r}}^{\mathrm{F}}$ is produced in region $\mathrm{r}$ using the Stuff imported from other regions, say, $s$ and t. Let $\mathrm{Q}_{\mathrm{rs}}$ and $\mathrm{Q}_{\mathrm{rt}}$ be respectively the intermediate input demand for Stuff from $s$ and $t$ by using region $r$. This leads us to write the CES production nest for $\mathrm{Q}_{\mathrm{r}}^{\mathrm{F}}$ as below:

$$
\mathrm{Q}_{\mathrm{r}}^{\mathrm{F}}=\mathrm{A}_{\mathrm{r}}^{\mathrm{F}}\left\{\delta_{\mathrm{r}}^{\mathrm{F}}\left(\mathrm{Q}_{\mathrm{rS}}\right)^{-\beta_{\mathrm{rF}}}+\left(1-\delta_{\mathrm{r}}^{\mathrm{F}}\right)\left(\mathrm{Q}_{\mathrm{r}}\right)^{-\beta_{\mathrm{rF}}}\right\}^{-1 / \beta_{\mathrm{rF}}}
$$

where $s, t \neq r ; s \neq t$. $\delta_{r}^{\mathrm{F}}$ is the distribution parameter associated with this production nest. The elasticity of substitution in $r$ between imported Stuffs is $\left[1 /\left(1+\beta_{\mathrm{rF}}\right)\right]$. If $\beta_{\mathrm{r} .}=\beta_{\mathrm{rF}},(2.1 \mathrm{~b})$ is equivalent to writing $\mathrm{Q}_{\mathrm{r} \text {. }}$ as a CES function in Stuff from all three sources.

Primary factor composite $\mathrm{Q}_{\mathrm{r}}^{\mathrm{V}}$ is produced combining the primary factors land $(\mathrm{T})$, labor $(\mathrm{L})$, and capital $(\mathrm{K}) \cdot \mathrm{Q}_{\mathrm{r}}^{\mathrm{f}}$ is the demand for primary factor $f$ in region $r$ where $f \in\{L, K, T\}$. The production technology is CES as given below:

$$
\mathrm{Q}_{\mathrm{r}}^{\mathrm{V}}=\mathrm{A}_{\mathrm{r}}^{\mathrm{V}}\left\{\Sigma_{\mathrm{f}} \delta \mathrm{V}_{\mathrm{rf}}\left(\mathrm{Q}_{\mathrm{r}}^{\mathrm{f}}\right)^{-\mathrm{Pr}_{\mathrm{r}}}\right\}^{-1 / \mathrm{P}_{\mathrm{r}}}
$$

where the $\delta_{\text {rf }}^{\mathrm{V}}$ are distribution parameters (positive fractions) (with $\Sigma_{\mathrm{f}} \delta_{\text {rf }}^{\mathrm{V}} \equiv$ $1, \forall \mathrm{r})$ and $\rho_{\mathrm{r}}$ is the substitution parameter. The substitution elasticity 
between primary factors in region $r$ is $\left[1 /\left(1+\rho_{\mathrm{r}}\right)\right]$. In the above equations, $A_{r}$, $\mathrm{A}^{\mathrm{F}}{ }_{\mathrm{r}}$ and $\mathrm{A}_{\mathrm{r}}^{\mathrm{V}}$ are technical progress parameters.

$\mathrm{Q}_{\mathrm{r}}$ and $\mathrm{Q}_{\mathrm{r}}^{\mathrm{V}}$ are combined using a fixed proportion technology with no scope for substitution between intermediate inputs and the primary factors. However, as seen above, there is scope for substitution between domestic and imported varieties of Stuff, as there is between L, K and T. At the top level the (Leontief) production function is:

$$
\mathrm{Y}_{\mathrm{r}}=[\mathrm{AO}]_{\mathrm{r}} \min \left\{\mathrm{A}_{\mathrm{r}}^{\mathrm{O}} \mathrm{Q}_{\mathrm{r} .}, \mathrm{Q}_{\mathrm{r}}^{\mathrm{V}}\right\}
$$

where $Y_{r}$ is the flow of final output and $A_{r}{ }_{r}$ is an intermediate-inputaugmenting technical change parameter. $[\mathrm{AO}]_{\mathrm{r}}$ is the Hicks-Neutral Technical Progress (HNTP) parameter. The entire production tree for this model is depicted in Figure1.

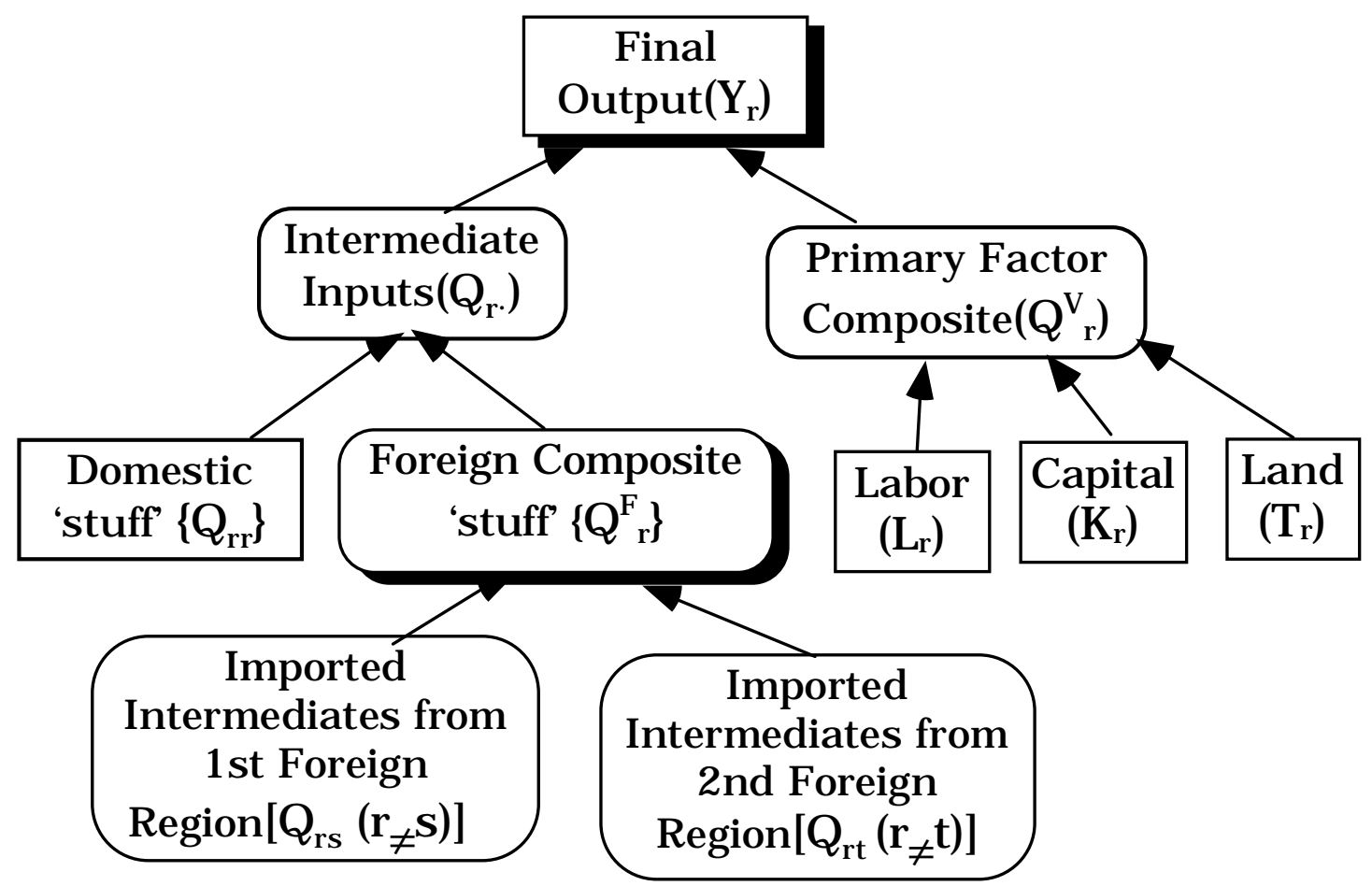

Figure 1: Production structure for region $\mathrm{r}$ in the one-commodity, three- region version of GTAP

\section{2b Spillover Equation and Productivity Shock}

The spillover hypothesis (as documented in Section 2.1 above) is captured by a technology-transmission equation incorporating destination-specific $\mathrm{AC}$ and source- and destination-specific SS. Exports from source $r$ to destination $\mathrm{s}$ determine an embodiment index $\mathrm{E}_{\mathrm{rs}}$. The latter, together with $\mathrm{AC}_{\mathrm{s}}$ and $\mathrm{SS}_{\mathrm{rs}}$ determine the value of a spillover coefficient $\gamma_{\mathrm{s}}\left(\mathrm{E}_{\mathrm{rs}}, \mathrm{AC}_{\mathrm{s}}, \mathrm{SS}_{\mathrm{rs}}\right)$ via the spillover function $\gamma_{\mathrm{s}}$. 
The details of this chain are now explained, starting at the top. Note that there is only one source of exogenous technological improvement in the current treatment, so that $\mathrm{r}$ is unique. ${ }^{7}$ Stuff produced using the improved technology embodies this technological improvement. Exports of Stuff from $r$ to the trade partners $s$ transmit these embodied technological advances but do not necessarily lead to enhancement of productivity in the recipient sectors of the client countries unless they are utilized as an input to production. We define an embodiment index $\mathrm{E}_{\mathrm{rs}}$ (where $0 \leq \mathrm{E}_{\mathrm{rs}} \leq 1$ ) that is proportional to the amount of embodied knowledge received via bilateral trade linkages between $r$ and $s$ so that

$$
\mathrm{E}_{\mathrm{rs}}=\mathrm{X}_{\mathrm{rs}} / \mathrm{Y}_{\mathrm{s}}
$$

where $X_{r s}$ is the bilateral exports of Stuff from source $r$ to the clients s and $Y_{s}$ is the domestic production of Stuff in $\mathrm{s}$. Thus $\mathrm{E}_{\mathrm{rs}}$ measures the amount of embodied knowledge obtained via bilateral exports from $r$ to $s$ per unit of output of Stuff produced in client s. ${ }^{8}$ The recipient-specific AC-index $\mathrm{AC}_{\mathrm{s}}$ (where $0 \leq \mathrm{AC}_{\mathrm{s}} \leq 1$ ) and the binary structural similarity index $\mathrm{SS}_{\mathrm{rs}}$ (where $\left.0 \leq \mathrm{SS}_{\mathrm{rs}} \leq 1\right)$ interactively determine a capture parameter $\theta_{\mathrm{s}}$ measuring the efficiency with which the knowledge embodied in bilateral trade flows from source $\mathrm{r}$ is captured by the recipients $\mathrm{s}:{ }^{9}$

$$
\theta_{\mathrm{s}}=\mathrm{AC}_{\mathrm{s}} \cdot \mathrm{SS}_{\mathrm{rs}}
$$

The productivity level realised from the potential streams of latest technology is dependent on $\theta_{\mathrm{s}} \in[0,1]$ with $\theta_{\mathrm{s}}=1$ implying full realisation of the foreign technology-induced productivity improvement. $\theta_{\mathrm{s}}$ and $\mathrm{E}_{\mathrm{rs}}$ jointly determine the value of the spillover coefficient $\gamma_{\mathrm{s}}\left(\mathrm{E}_{\mathrm{rs}}, \theta_{\mathrm{s}}\right)$ for the destination s. $\gamma_{\mathrm{s}}($.$) is a strictly concave function of \mathrm{E}_{\mathrm{rs}}$ with the properties that

$$
\gamma_{\mathrm{s}}(0)=0 ; \gamma_{\mathrm{s}}(1)=1 ; \gamma_{\mathrm{s}}^{\prime}=\left(1-\theta_{\mathrm{s}}\right) \mathrm{E}_{\mathrm{rs}}{ }^{-\theta_{\mathrm{s}}}>0 ; \gamma_{\mathrm{s}}^{\prime \prime}=-\theta_{\mathrm{s}}\left(1-\theta_{\mathrm{s}}\right) / \mathrm{E}_{\mathrm{rs}}{ }^{1+\theta \mathrm{s}}<0 ;
$$

where primes indicate the first (') and the second (") derivatives with respect to $\mathrm{E}_{\mathrm{rs}}$.

7 An implication of the uniqueness of $r$ is that equations carrying an $r$-subscripted variable on the right do not necessarily require an $r$ subscript to appear on the left.

8 However, it is to be noted that in MT, Ers is defined as the ratio of bilateral trade flows (Xrs) from $r$ to $s$ in any final product sector and total bilateral trade flows ( $\left.\sum \mathrm{sXrs}\right)$ to all destinations $s$ from the source $r$. This ratio shows the spillover to the recipients as a proportion of aggregate 'global' spillovers from source to the client countries. This seems to neglect the public good character of knowledge capital. We have modified this definition as described in the text.

9 It has already been mentioned in footnote 5 that $\mathrm{AC}$ depends on several factors which we set aside in our present discussion. Depending on those factors, AC could be 'endogenously' determined via a function where these determinants combine to produce a scalar AC-index. In the current treatment, for sake of simplicity, $\mathrm{AC}$ is exogenously specified and related to an arbitrarily specified Human Capital index. SS is also exogenous. 
We shall consider an exogenous TFP improvement in the technology for producing Stuff in region r. Specifically, the shock is a Hicks-neutral improvement in the productivity of each primary factor there.

Figure 2 shows the way in which technological knowledge embodied in trade flows affects the spillover of productivity from a source to a destination region.

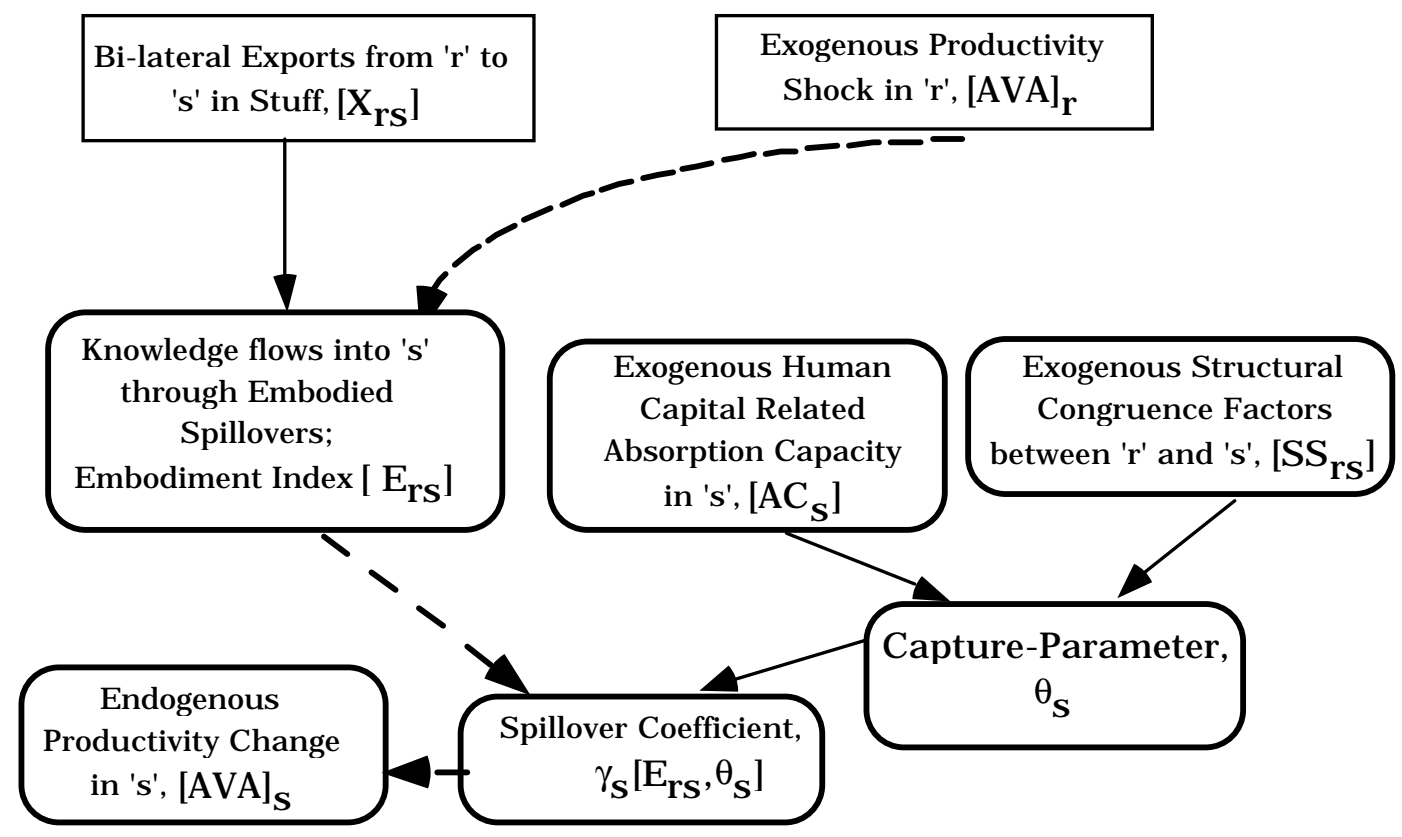

Figure 2: Flow chart for the transmission mechanism in the model

The improvement in productive efficiency leads to value-added augmenting technical change in Stuff. Hence, $\mathrm{A}_{\mathrm{r}}^{\mathrm{V}}$ in the value-added nest of the production tree [see equation (2.2)] is the appropriate technological change parameter for considering HNTP. In GTAP notation, this is AVA(r). The transmission equation showing how the productivity improvement in $r$ affects productivity in $\mathrm{s}$ is as follows:

$$
\operatorname{ava}(\mathrm{s})=\gamma_{\mathrm{s}}\left(\mathrm{E}_{\mathrm{rs}}, \theta_{\mathrm{s}}\right) \cdot \operatorname{ava}(\mathrm{r})
$$

where ava(s) and ava(r) are respectively the percentage improvements in the productivity 'levels' (HNTP parameters, AVA) in the value-added nest of the production function of regions $r$ and $s$ (the convention in the GTAP system of notation being that the lower case variables represent the percentage changes in the corresponding 'level' variables). This transmitted improvement is higher, the higher are the values of $\mathrm{AC}_{\mathrm{s}}$ and $\mathrm{SS}_{\mathrm{rs}}$. More specifically,

$$
\gamma_{\mathrm{s}}\left(\mathrm{E}_{\mathrm{rs}}, \theta_{\mathrm{s}}\right)=\mathrm{E}_{\mathrm{rs}}^{1-\theta_{\mathrm{s}}}, 0 \leq \theta_{\mathrm{s}} \leq 1
$$


Given the functional form, $\gamma_{\mathrm{s}}\left(\mathrm{E}_{\mathrm{rs}}, \theta_{\mathrm{s}}\right) \leq \mathrm{E}_{\mathrm{rs}} \leq 1$ for $0<\theta_{\mathrm{s}}<1,0 \leq \mathrm{E}_{\mathrm{rs}} \leq 1$ and $\frac{\partial \gamma_{\mathrm{s}}^{\prime}}{\partial \theta_{\mathrm{s}}}=-\mathrm{E}_{\mathrm{rs}}^{-\theta_{\mathrm{s}}}\left[1+\ln \gamma_{\mathrm{s}}\right]<0 . \frac{\partial \gamma_{\mathrm{s}}^{\prime}}{\partial \theta_{\mathrm{s}}}<0$ implies that marginal returns of $\gamma_{\mathrm{s}}$ to $\mathrm{E}_{\mathrm{rs}}$ are a decreasing function of $\theta_{\mathrm{s}}$. It can also be shown that $\frac{\partial \gamma_{\mathrm{s}}}{\partial \theta_{\mathrm{s}}}=\left[-\gamma_{\mathrm{s}}\left(\mathrm{E}_{\mathrm{rs}}\right) \cdot \ln \mathrm{E}_{\mathrm{rs}}\right]>0$ and $\frac{\partial^{2} \gamma_{\mathrm{s}}}{\partial \theta_{\mathrm{s}}^{2}}=\left[\left(\operatorname{lnE}_{\mathrm{rs}}\right)^{2} \cdot \mathrm{E}_{\mathrm{rs}}{ }^{1-\theta}{ }_{\mathrm{s}}\right]>0$; i.e., $\gamma_{\mathrm{s}}$ is a convex function of $\theta_{\mathrm{s}}$. Thus, the $\gamma_{\mathrm{s}}$ function shows increasing marginal returns to $\theta_{\mathrm{s}}{ }^{10}$

Substitution of (2.7) into (2.6) shows that, all told, the equation governing the technological spillover is given by

$$
\operatorname{ava}(\mathrm{s})=\mathrm{E}_{\mathrm{rs}}{ }^{1-\mathrm{AC}_{\mathrm{s}} \mathrm{Ss}_{\mathrm{rs}}} \text {. ava(r) }
$$

Substitution of (2.4) into equation (2.8) yields the fundamental spillover equation for implementation in GTAP as

$$
\operatorname{ava}(\mathrm{s})=\left[\mathrm{X}_{\mathrm{rs}} / \mathrm{Y}_{\mathrm{s}}\right]^{1-\mathrm{AC}_{\mathrm{s} .} \mathrm{SS}_{\mathrm{rs}}} \cdot \operatorname{ava}(\mathrm{r})
$$

Being 'neutral' in nature, the exogenous HNTP shock uniformly reduces the input requirements associated with producing a given level of output of Stuff. ${ }^{11}$

\section{The GTAP Database and Aggregation}

The aggregation procedure involves working in several steps with the computer files necessary for this task. All these files are documented in detail in the Appendix.

\subsection{Set Aggregation}

The MODHAR programme available in the Windows version [WINGEM] of GEMPACK (General Equilibrium Modelling Package) was run interactively to create an HAR (Header ARray) file named SET1BY3.HAR from a text file (SET1BY3.TXT) defining the elements of the sets. Table 3.1.1 displays the changes made in the existing SET specifications in the $3 \times 3$ database for commodity aggregation.

10 With the determinants $\mathrm{AC}$ and SS of $\theta \mathrm{s}$ both bounded in $[0,1]$ and strictly exogenous, this should not present any computational problem in our GE model.

11 In our current treatment, we do not consider biased technical change of any variety. This rules out closures of the model that correspond to a balanced-growth path (as investigated by Walmsley (1998)). Apart from the exceptional case of a Cobb-Douglas production function, under such closures the only valid sustained technological shock is one which is laboraugmenting (Harrod-Neutral)—see Barro and Sala-I-Martin (1995, Ch 1.) or Powell and Murphy (1997, pp. 97-103);. 
TABLE 3.1.1 List of sets and their elements in $1 \times 3$ GTAP

\begin{tabular}{lcc}
\hline \multicolumn{1}{c}{ Set } & Description & Elements \\
\hline REG & Regions & USA, EU, ROW \\
SRC & Source of Invention & USA \\
REG_NOT_SRC & Spillover Destinations & EU, ROW \\
PROD_COMM & Produced Commodities & Stuff, Capital Goods (CGDS) \\
TRAD_COMM & Traded Commodities & Stuff \\
ENDW_COMM & Endowment Commodities & Land, Labor, Capital \\
DEMD_COMM & Demanded Commodities & Land, Labor, Capital, Stuff \\
CGDS_COMM & Capital Goods Commodities & Capital Goods (CGDS) \\
NSAV_COMM & Non-savings Commodities & Land, Labor, Capital, Stuff, CGDS \\
\hline
\end{tabular}

\subsection{Database Aggregation}

We refer to our one-traded-commodity, three-region model as $1 \times 3$ GTAP. The aggregated database comprising trade, production and input-output data was produced by running Mark Horridge's programme DAGG on the $3 \times 3$ GTAP bilateral and input-output data in Version 3 of the data-base as used in GTAP short courses held in August, 1996. It involved a three step procedure as described in details in the Appendix. This database is checked for macro-balance by ensuring that (i) the zero pure profit condition is satisfied; (ii) GDP from the income and expenditure sides match each other.

\subsection{Modification of Parameter Setting}

The additional parameters introduced in the parameter file are $\mathrm{HK}(\mathrm{s})$ and $\mathrm{SS}(\mathrm{r}, \mathrm{s})$. HK(s) represents $\mathrm{AC}_{\mathrm{s}}$ as described in Section 2. Their values are set arbitrarily. Assuming that the EU is more similar to the US in both SS and $\mathrm{AC}$ than to the ROW, higher values are assigned for these exogenous variables in case of $\mathrm{EU}$ as compared to ROW; that is, $\mathrm{AC}_{\mathrm{EU}}>\mathrm{AC}_{\mathrm{ROW}}$ and $\mathrm{SS}_{\mathrm{EU}, \mathrm{US}}>\mathrm{SS}_{\mathrm{ROW}, \mathrm{US}}$. The Appendix documents them as appended in the TABLO file. The values for the elasticity of substitution parameters (see Table 3.3.1) are assumed to be common across all the regions. 
TABLE 3.3.1 Value of elasticities of substitution parameters*

\begin{tabular}{|l|c|c|c|}
\hline Elasticity of Substitution & \multicolumn{3}{|c|}{ Value } \\
\hline $\begin{array}{l}\text { ESUBD (Armington substitution } \\
\text { elasticity between } \mathrm{Q}_{\mathrm{rr}} \text { and } \mathrm{Q}_{\mathrm{r}}^{\mathrm{r}} \text { ) }\end{array}$ & 2.5 & 2.5 & 2.5 \\
\hline $\begin{array}{l}\text { ESUBM [Armington substitution } \\
\left.\text { elasticity between } \mathrm{Q}_{\mathrm{r}}(\mathrm{r} \neq \mathrm{s}) \text { and } \mathrm{Q}_{\mathrm{rt}}(\mathrm{r} \neq \mathrm{t})\right]\end{array}$ & 5.0 & 5.0 & 5.0 \\
\hline $\begin{array}{l}\text { ESUBVA (substitution elasticity } \\
\text { among } \mathrm{L}_{\mathrm{r}}, \mathrm{K}_{\mathrm{r}}, \mathrm{T}_{\mathrm{r}} \text { in CES-nest of } \\
\text { primary factors) }\end{array}$ & 1.0 & 1.0 & 1.0 \\
\hline
\end{tabular}

- Refer to figure 1 for notation.

\section{GTAP Implementation}

\subsection{Additional Equation}

The economic model is the one described in Hertel (ed.) (1997) with an additional behavioural equation, two new parameters and two new coefficients, plus some additional national accounting identities coded by Philip D. Adams. Equation (2.8a) in the notation of the GTAP-system of equations is:

$$
\operatorname{ava}(\mathrm{i}, \mathrm{s})=[\operatorname{VXWD}(\mathrm{i}, \mathrm{r}, \mathrm{s}) / \operatorname{VOW}(\mathrm{i}, \mathrm{s})]^{\left(1-\mathrm{AC}_{\mathrm{S}} \cdot \mathrm{Ss}_{\mathrm{rs}}\right)} \cdot \operatorname{ava}(\mathrm{i}, \mathrm{r})
$$

where $i \in$ TRAD_COMM. TRAD_COMM contains traded commodity Stuff only, VXWD(i,r,s) is the value of exports of tradable commodity i from $r$ to $s$ evaluated at world $f o b$ prices [i.e., $\mathrm{X}_{\mathrm{rs}}$ in equation (2.8a)]; $\operatorname{VOW}(\mathrm{i}, \mathrm{s})$ is the value of output of tradable commodity $\mathrm{i}$ in s evaluated at world $f o b$ prices [i.e., $\mathrm{Y}_{\mathrm{s}}$ in (2.8a)]. The model is encoded in TABLO language for GEMPACK software as reported in the Appendix. In our implementation, we define one region at a time as the source of invention - set named SRC. The countries other than the source belong to the set named REG_NOT_SRC. These two sets are subsets of the set of all regions-REG. Table 4.1.1 gives the encoding of the spillover equation (i.e., equation (2.8b)) in TABLO ${ }^{12}$ language.

12 TABLO is an algebraic language for writing economic models and for defining the associated sets, equations, coefficients, and variables for subsequent solution specifically compatible with the GEMPACK software suite (see Harrison and Pearson, 1996). 


\title{
TABLE 4.1.1 Additional equation in the TABLO source
}

\section{file for technology spillover}

\author{
Equation MOD_EMB_SPLOVER \\ !This equation gives the Embodied Spillovers via Trade in the recipients! \\ (all, i, TRAD_COMM) (all, r, SRC) (all, s, REG_NOT_SRC) \\ $\operatorname{ava}(\mathrm{i}, \mathrm{s})=\left[(\mathrm{VXWD}(\mathrm{i}, \mathrm{r}, \mathrm{s}) / \operatorname{VOW}(\mathrm{i}, \mathrm{s}))^{\wedge}(1-\mathrm{HK}(\mathrm{s}) * \mathrm{SS}(\mathrm{r}, \mathrm{s}))\right]^{*}$ ava $(\mathrm{i}, \mathrm{r})$;
}

The Appendix documents the changes made in the GTAP96.TAB by defining some additional coefficients, variables and necessary equations.

\subsection{Closure and Shock}

In the version of GTAP we have used, there is no financial sector. A global 'bank' collects regional saving into a hypothetical global saving pool. Saving in each region is conceptually a real 'saving commodity' (qsave). After each region receives an allocation of the saving commodity from the global saving pool, it uses the purchasing power so obtained to create new capital. The commodity composition of this new investment ( $q c g d s)$ is region-specific.

All savers face a common price, PSAVE (which is the numeraire in the standard closure of the model), for the savings commodity. The allocation of savings commodity depends on the specification of the closure. Here it is assumed that the aggregate capital stock is exogenous in all regions and that regional and global nett investment move together. While no reallocation of regional shares in global investment is permitted, interindustry capital mobility within a region is allowed. This is known as the medium-run, or partial long-run equilibrium standard closure in the GTAP literature.

The parameter RORFLEX(r) determines the sensitivity of regional rates of return to these changes in regional gross investment. Here it is assumed that all regions have $\operatorname{RORFLEX}(\mathrm{r})=10$.

In all standard closures of GTAP, the regional labor endowments are exogenous, while in the current closure new investment does not add to the capital stock available in the solution period ${ }^{13}$. Hence the productive capacities of all regions are unaffected in the period to which the simulation results apply. However, as investment is a component of final demand, it affects economic activity in the solution period via its impact on demand. In

13 We use 'solution period' and 'snapshot' period interchangeably to mean the period (occurring some time after the shock) for which the simulation is run and solution is obtained. Specifically, we introduce one or more sustained shocks at an initial period and maintain them through until the 'snapshot' period is reached. The solution is presented as the percentage deviation in the snapshot period in a variable of interest relative to its value in that period in a base-case or control scenario in which no shocks occur. 
the case of our $1 \times 3$ macro aggregation of GTAP, these compositional influences are limited to the sourcing of Stuff from different regions in the assembly of locally-specific capital goods.

The notion of TFP improvement in the CGDS sector is not valid as CGDS assembles the Armington substitutable Stuffs for capital formation without using any primary factors of production. Moreover, CGDS is produced and sold solely in the domestic market, and so is non-traded. Whilst the sector's costs are affected by TFP changes in the three sources of Stuff, CGDS itself plays no role in the technology transfer process.

Below we consider an arbitrary 2 per cent TFP shock in the USA in the Stuff sector. In the closure used here, prices, quantities of all nonendowment commodities, and regional incomes are endogenous, while policy variables, other technical change variables, and population [POP(r)] are exogenous to the model.

\section{Analysis of Simulation Results}

\subsection{Macroeconomic Effects in Each Region}

Table 5.1.1 summarises the impact of the perturbation on the macro variables. The flow chart in Figure 3 displays a schematic presentation of the simulation results for the macro-variables in the model.

With fixed supplies of land, labor and capital and no factor-bias, a 2 per cent TFP-shock in Stuff in the USA leads to an increase in output in that sector and real GDP at factor cost of exactly 2 per cent. After the HNTP shock, we effectively have 2 per cent more of each factor after allowing for the improvement in its quality. Thus, in the snapshot period, one-hundred input-hours of composite real value-added are equivalent to one hundred and two quantity units of composite value-added measured in terms of constant efficiency units applicable in the base-period. Hence, there has been no change in the usage of primary factors of production (as measured in conventional units) between the base case and the shocked solution. This leads to a zero percentage change in value-added (not quality adjusted) by factors of production [row 6, Table 5.1.1]. However, real value-added (measured in constant efficiency units) increases in all three regions.

The increase in productive efficiency of the raw primary composite input (measured in conventional units) leads to an increase in its marginal productivity (MP) - i.e., 2.00, 1.07, and 0.05 per cent for USA, EU and ROW respectively ${ }^{14}$. Since factors are paid according to their marginal

14 The percentage changes in marginal (physical) productivities can be verified from computed GTAP variables as follows. In the levels, the value of the MPs of factors should equal their prices:

$$
\mathrm{P}_{\text {stuff }} * \mathrm{MP}_{\mathrm{f}}=\mathrm{P}_{\mathrm{f}} \quad(\text { where } \mathrm{f} \in\{\mathrm{L}, \mathrm{K}, \mathrm{T}\})
$$


TABLE 5.1.1 Simulated regional effects of technological change in the USA on selected macroeconomic variables

Percentage change in:

1. Total factor productivity [TFP]

2. Output of STUFF [qo]

3. Supply price of STUFF [ps]

4. Output of sector CGDS [qcgds]

5. Price of investment goods [pcgds]

6. Real Value-added in Stuff [qva] (in conventional units)

7. Price of Value-added [pva] (in conventional units)

8. Real Value-added in Stuff [in constant efficiency units]

9. Price of Value-added [in constant efficiency units]

10. Nominal GDP [NA_gdpinc] from Income Side (market prices)

11. Nominal GDP from Expenditure Side [NA_gdpexp] (market prices)

12. Nominal GDP at Factor Cost [NA_gdpfc]

13. Real GDP from Income side [NA_realgdpinc] (at market prices)

14. Real GDP from Expenditure side [qgdp] (at market prices)

15. Real GDP at Factor Cost [NA_realgdpfc]

16. Price Index of GDP [NA_prigdpin] from Income side (market prices)

17. Price index of GDP from expenditure side[NA_prigdp] (market prices)

18. Price Index of GDP at Factor Cost [NA_prigdpfc] ${ }^{(a)}$

19. Price index for GNE [NA_prigne]
USA EU ROW

$\begin{array}{lll}2.00 & 1.07 & 0.05\end{array}$

$2.00 \quad 1.07 \quad 0.05$

$\begin{array}{lll}-0.30 & -0.19 \quad+0.12\end{array}$

$\begin{array}{lll}0.08 & 0.19 & 0.25\end{array}$

$\begin{array}{lll}-0.26 & -0.17 \quad+0.09\end{array}$

$\begin{array}{lll}0.00 & 0.00 \quad 0.00\end{array}$

$\begin{array}{lll}1.68 & 0.86 & 0.19\end{array}$

$2.00 \quad 1.07 \quad 0.05$

$\begin{array}{lll}-0.31 & -0.20 \quad+0.14\end{array}$

$\begin{array}{lll}1.67 & 0.86 & 0.19\end{array}$

$\begin{array}{lll}1.67 & 0.86 & 0.19\end{array}$

$\begin{array}{lll}1.68 & 0.86 & 0.19\end{array}$

$1.99 \quad 1.06 \quad 0.06$

$1.99 \quad 1.06 \quad 0.06$

$\begin{array}{lll}2.00 & 1.07 \quad 0.05\end{array}$

$\begin{array}{lll}-0.31 & -0.20 \quad+0.14\end{array}$

$\begin{array}{lll}-0.31 & -0.20 \quad+0.14\end{array}$

$\begin{array}{lll}-0.31 & -0.20 \quad+0.14\end{array}$

$\begin{array}{lll}-0.28 & -0.18+0.10\end{array}$

\# These values are for percentage changes of level variables from their control values (postshock). Figures are rounded to 2 or 3 decimal places. The shock is a 2 per cent increase in TFP.

(a) Figures for row 18 are obtained by modifying the existing equation for it in GTAP National Accounts module à la Adams (1996) and incorporating into it the 'Tec_Chg' variable as documented in the Appendix. These are the same as figures in row 9 after this adjustment has been made.

We have computed GTAP results for the percentage changes in $\mathrm{P}_{\text {stuff }}$ and in each $\mathrm{P}_{\mathrm{f}}-\mathrm{p}_{\text {stuff, }}, \mathrm{p}_{\mathrm{L}}$, $\mathrm{p}_{\mathrm{K}}$, and $\mathrm{p}_{\mathrm{T}}$ (say) - in each region. Then, for example, we can use the above relationship to compute the percentage change in the marginal physical product of labour by:

per cent change in $\mathrm{MP}_{\mathrm{L}}=\left(\left\{\left[\mathrm{P}_{\mathrm{f}}{ }^{(\text {initial })} *\left(1+\mathrm{p}_{\mathrm{f}} / 100\right)\right] /\left[\mathrm{P}_{\text {stuff }}{ }^{\text {(initial) }} *\left(1+\mathrm{p}_{\text {stuff }} / 100\right)\right]\right\}-1\right) * 100$

$$
=100 *\left[\left\{\left(\mathrm{p}_{\mathrm{f}} / 100\right)-\left(\mathrm{p}_{\text {stuff }} / 100\right)\right\} /\left(1+\mathrm{p}_{\text {stuff }} / 100\right)\right]
$$

Note that this accurate calculation is not replicated by simply subtracting ' $\mathrm{p}_{\text {stuff }}$ ' from ' $\mathrm{p}_{1}$ '. 


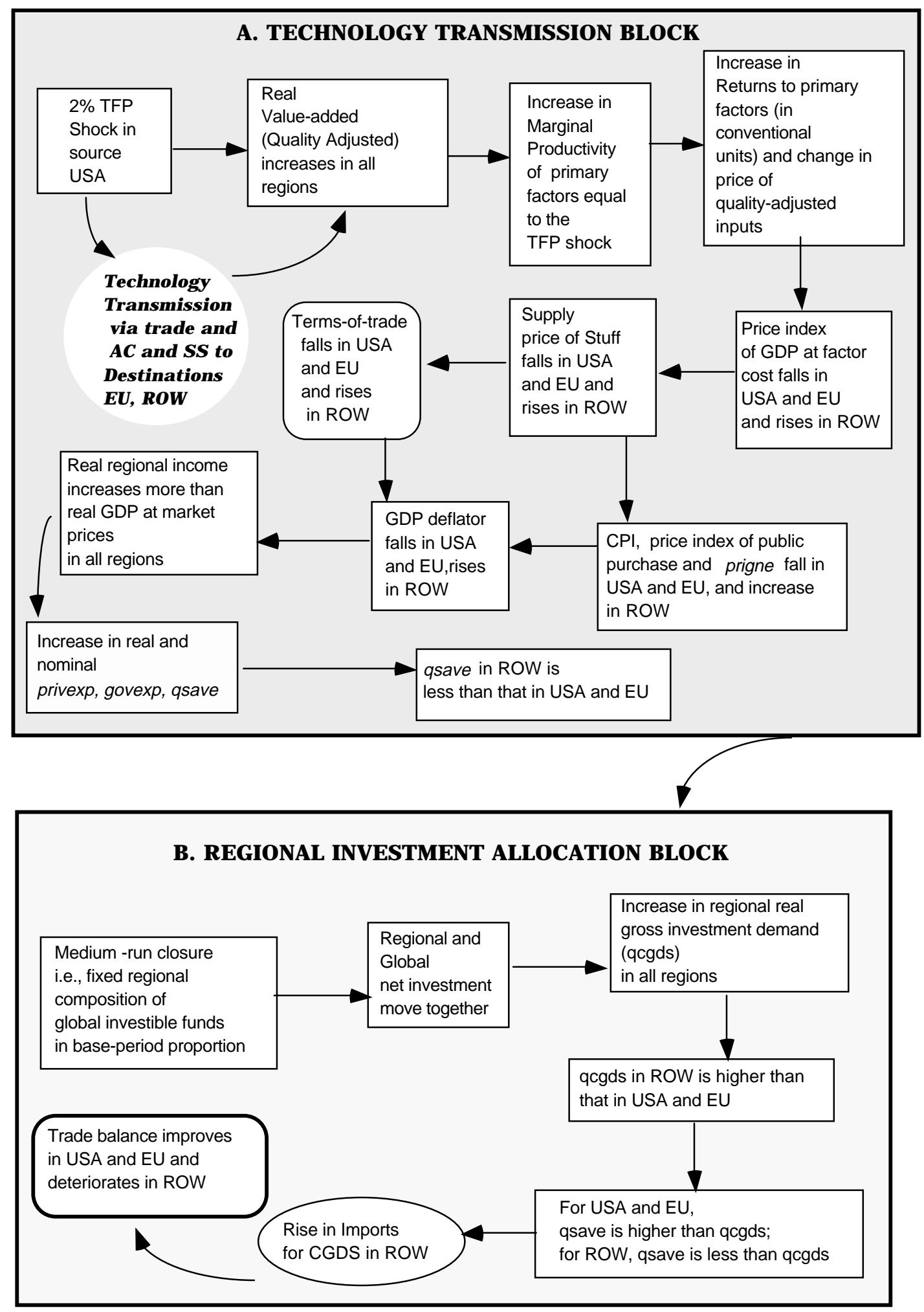

Figure 3: Flow chart showing the principal pathways behind the results 
products, these increases in MP lead to increases in the price of value-added and their constituents in all three regions. Being neutral in nature, this TFP improvement causes equal percentage increases in the real rewards of all primary factors within any given region.

We observe that there has not been full transmission of technical change from the source to the destinations - EU and ROW. Table 5.1.2 suggests that the value of the spillover coefficient depends more strongly on $\theta_{\mathrm{s}}$ than on $\mathrm{E}_{\mathrm{rs}}$ alone. Thus, whilst trade is the prime vehicle for transmission of knowledge flows, $\mathrm{AC}_{\mathrm{s}}$ and $\mathrm{SS}_{\mathrm{rs}}$ (and hence, $\theta_{\mathrm{s}}$ ) are critical for effective transmission of technology from $r$ to $s$. This is supported by the fact that even when $E_{\mathrm{rs}}$ has lower values, the magnification of them by $\theta_{\mathrm{s}}$ can lead to a high rate of capture of the technological improvement. Thus, EU with higher values of both $\mathrm{AC}_{\mathrm{s}}$ and $\mathrm{SS}_{\mathrm{rs}}$, does better than ROW at capturing the TFP improvement occurring in the USA despite ROW having a higher value of $\mathrm{E}_{\mathrm{rs}}$. Consequently, in Table 5.1.1 we see a greater improvement in technology in EU (1.07) as compared to that in ROW (0.05).

TABLE 5.1.2 Values of embodiment index, spillover coefficient and capture-parameter ${ }^{\text {(a) }}$

\begin{tabular}{|c|c|c|c|}
\hline $\begin{array}{c}\text { GTAP } \\
\text { Regions }\end{array}$ & $\begin{array}{c}\text { Embodiment } \\
\text { Index } \\
\left(\mathrm{E}_{\mathrm{rs}}\right)\end{array}$ & $\begin{array}{c}\text { Spillover } \\
\text { Coefficient } \\
\left(\gamma_{\mathrm{s}}\right)\end{array}$ & $\begin{array}{c}\text { Capture- } \\
\text { Parameter } \\
\left(\theta_{\mathrm{s}}\right)\end{array}$ \\
\hline EU & 0.014 & 0.540 & 0.855 \\
\hline ROW & 0.020 & 0.023 & 0.030 \\
\hline USA & 1.000 & 1.000 & 1.000 \\
\hline
\end{tabular}

(a) Values shown relate to the pre-shock situation.

Stuff being the only sector whose production involves value-added, its share in total value-added is unity in all three regions. As the TFP improvements cause real value-added by factors of production (quality adjusted) to increase by the same percentages, the percentage change in real GDP at factor cost in each region is equal to the respective TFP shock (see rows 1 and 8, Table 5.1.1). Also, the price indexes for value-added in Stuff (row 9 of Table 5.1.1) and for GDP at factor cost (row 18) are identical. Changes in real nett indirect taxes (which are of fairly small magnitude) account for the wedges between real GDP at market prices and real GDP at factor cost.

Now, the recorded nominal GDP at factor cost [NA_gdpfc] (row 12, Table 5.1.1) is calculated on the basis of price and quantity indexes of valueadded measured in conventional units $[p v a]$. These are taken as given from the GTAP results. As the real value-added measured in constant efficiency units (i.e., 'quality-adjusted') increases in all regions by the same percentage 
as the TFP improvement, the effective price of value-added has to adjust accordingly so that the nominal value-added measured in constant efficiency units matches the GTAP results. The increases in real value-added (measured in constant efficiency units) of about 2 and 1 per cent respectively in USA and EU lead to falls in the corresponding price indices of about 0.3 and 0.2 per cent (rows 8 and 9, Table 5.1.1). In case of ROW, the small rise in real value-added (with least TFP improvement) is not enough to depress the corresponding price given the attendant general equilibrium effects (to be discussed below) - in fact, it rises there by 0.14 per cent.

\subsection{Inter-regional Competition Effects}

Table 5.2.1 shows that, region by region, there have been increases in nominal regional household income $[y(r)]$ and its uses (rows $1,7,5$ and 4). We first explain post-shock differential impacts on nominal income [y(r)] which is the sum of primary factor payments and receipts from various transactions taxes nett of depreciation. Table 5.2.2 breaks up the componentwise effects on $y(r)$. Earlier discussion shows that the HNTP shock increases ' $p v a$ ' and its components (row 7, Table 5.1.1). The increase in $y(r)$ has primarily been caused by the uniform increases in primary factor payments in all regions (row 2, Table 5.2.2).

With fixed regional supplies of capital stocks at the beginning of the solution period, ex post there have been no percentage changes in it and hence none in physical depreciation (row 3). Changes in the price of capital goods ( $p c g d s$ ) cause a revaluation of existing capital stock; however, capital gains/losses do not enter into our definition of regional income. But changes in pcgds affect the cost of capital consumption, which enters our income definition as a debit. As pcgds falls in the USA and EU (row 5, Table 5.1.1), the replacement cost of existing capital goods falls in these regions (row 4, Table 5.2.2), contributing small rises to nett incomes. In case of ROW, the increase in pcgds causes the nominal cost of replacing depreciated capital to go up and this, in turn, dampens the effect of the small increase in endowment income. With exogenously fixed tax rates, the changes in prices reflect only the effects of the TFP shock per se. Given output tax rates, an increase in output causes a rise in tax revenues on commodities (row 5, Table 5.2.2). 
TABLE 5.2.1 Simulated regional effects on sources of final demand ${ }^{\Theta}$

\begin{tabular}{|l|c|c|c|}
\hline \multicolumn{1}{|l|}{ Percentage change in: } & USA & EU & ROW \\
\hline 1. Regional household income [y (REG)] (Nominal) & 1.91 & 1.00 & 0.21 \\
\hline $\begin{array}{l}\text { 2. Price index of GDP from expenditure and income } \\
\text { sides(market prices) }\end{array}$ & -0.31 & -0.20 & +0.14 \\
\hline 3. Regional household income [u (REG) ] (Real) & 2.19 & 1.17 & 0.12 \\
\hline $\begin{array}{l}\text { 4.Regional nett savings demand [qsave] (Real and } \\
\text { nominal) }\end{array}$ & 1.91 & 1.00 & 0.21 \\
\hline 5. (Real) Public consumption [ug (REG)] & 2.20 & 1.19 & 0.09 \\
\hline 6. Nominal Public consumption [yg(r)] & 1.91 & 1.00 & 0.21 \\
\hline 7. Nominal Private household expenditure [yp(REG)] & 1.91 & 1.00 & 0.21 \\
\hline 8. (Real) Private household consumption [up (REG)] & 2.19 & 1.18 & 0.10 \\
\hline 9. Gross National Expenditure (NA_realgne ] (Real) & 1.92 & 0.99 & 0.14 \\
\hline 10. Price index for GNE [NA_prigne] & -0.28 & -0.18 & +0.10 \\
\hline 11. McDougall Terms-of-trade (McDougall_TOT) & -0.35 & -0.21 & +0.17 \\
\hline 12. Aggregate export price index of Stuff [pxw] & -0.30 & -0.19 & +0.12 \\
\hline 13. Aggregate import price index of Stuff [piw] & +0.05 & +0.02 & -0.05 \\
\hline 14. Real value of exports [qxw] & 1.71 & 1.19 & 0.05 \\
\hline 15. Real value of imports [qiw] & 1.01 & 0.50 & 0.46 \\
\hline 16. Change in trade balance [DTBAL] & +1508.26 & +3233.6 & -4741.86 \\
\hline 17. Consumer price index [ppriv] & -0.277 & -0.179 & +0.104 \\
\hline 18. Government aggregate purchase price index [pgov] & -0.285 & -0.189 & +0.110 \\
\hline $\begin{array}{l}\text { 19. Real GDP from Expenditure and Income sides } \\
\text { (market prices) }\end{array}$ & 1.99 & 1.06 & 0.06 \\
\hline 20. Real Gross regional investment [qcgds] & 0.08 & 0.19 & 0.25 \\
\hline Figurs & & & \\
\hline
\end{tabular}

$\Theta$ Figures in this table are rounded to 2 or, 3 decimal places.

$\Phi$ This is the same in 'nominal' terms as there has been no per cent-change in its price PSAVE.

$\psi$ Since the trade balance can pass through zero, percentage changes are avoided in the case of this variable. The change reported here is an ordinary change (million US \$) changes of level values. 
TABLE 5.2.2 Simulated effects on nominal regional income ${ }^{(b)}$

\begin{tabular}{|l|c|c|c|}
\hline \multicolumn{1}{|c|}{ Percentage change in: } & USA & $E U$ & $R O W$ \\
\hline 1. Nominal Regional Household income [y(REG)] & 1.908 & 1.000 & 0.206 \\
\hline 2. Contribution of Endowment income [pfac] & 1.721 & 0.936 & 0.193 \\
\hline $\begin{array}{l}\text { 3. Contribution of Physical Depreciation } \\
\text { 4. Contribution of pcgds to cost of replacing depreciated } \\
\text { capital (nominal changes) }\end{array}$ & 0.000 & 0.000 & 0.000 \\
\hline 5. Contribution of Output tax revenues & 0.031 & +0.024 & -0.013 \\
\hline
\end{tabular}

(b) Figures in this table are rounded to 3 or, 4 decimal places. Figures in row 1, when rounded to 2 decimal places, yield the same figures as in row 1 of Table 5.2.1. We do not report here the figures for all component-wise effects from tax receipts. Figures of very small magnitude $(<0.00003)$ are excluded.

We now turn to the discussion of impacts on sources of various income uses.

\section{2.a Region-wide impact on sources of final demands}

In GTAP, each region's demands for private expenditure [PRIVEXP(r)], public expenditure [GOVEXP(r)] and saving [SAVE(r)] are determined by maximisation of a per capita Cobb-Douglas utility function subject to the constraint that these three items totally exhaust the regional income [INCOME(r)]. Under this specification, their fixed shares of income result in the equality of percentage increases in nominal demand for the income uses with the percentage increases in total nominal income.

In the present closure with PSAVE as the numeraire, the percentage increase qsave is the same as that in nominal income and changes in real and nominal saving, qsave, are the same.

Given the equality of percentage changes in the nominal variables ${ }^{15}$ PRIVEXP and GOVEXP in each region, we observe that the corresponding real variables in each region move together but not strictly in proportion to each other (see rows 5 and 7, Table 5.2.1). The changes in real consumption expenditures are attributed to the differential impacts of movements in pgov (the aggregate government purchase price index) and ppriv (the consumer price index or, $\mathrm{CPI}$ - - the divergence being caused by the diverse purchase patterns of the private and public 'households'16. Back-of-the-envelope calculation shows that changes $u p(r)$ and $u g(r)$ are almost exactly the differences between percentage changes in nominal PRIVEXP and

15 In terms of the TABLO file, strictly speaking, PRIVEXP and GOVEXP are coefficients which are equal to the levels values of the variables 'yp' and ' $y g$ '. The latter one is added in the original TABLO file for computational conveniences.

16 According to base-period data, the share of domestic Stuff in government consumption is 96 per cent for USA, 99 per cent for EU and 97 per cent for ROW. This is higher than that in the private sector's consumption - 95 per cent for USA, 96 per cent for EU, and 93 per cent for ROW. As well, the regional composition of imported Stuff differs between the two categories of consumption. 
GOVEXP (rows 6 and 7, Table 5.2.1) and ppriv and pgov respectively (rows 17 and 18, Table 5.2.1).

The private household price index $(p p)$ and government household price index $(p g)$ are both share weighted averages of percentage changes in a composite import price index and in a domestic price index for domestic Stuff at purchaser's prices. For each category of consumption, domestically-sourced Stuff represents a larger share (on an average 96 per cent for GOVEXP and 93 per cent for PRIVEXP) than composite imports in all three regions.

With domestically sourced Stuff dominating the CPI in every region, the falls in the price of Stuff in USA and EU by 0.30 and 0.19 per cent respectively translate into declines in the CPI in these two regions of 0.28 and 0.18 per cent respectively. Similar considerations explain the slightly larger falls of the pgov in these two countries - compare rows 17 and 18 in Table 5.2.1. For ROW, on the other hand, the increase in the price of domestic Stuff by 0.12 per cent leads to a 0.10 per cent increase in the CPI whereas pgov registers a slightly larger percentage rise (0.11) there.

Now, the percentage increases in real private and public consumption demand for composite Stuff are larger than the corresponding increases in domestic supply in every region (rows 5 and 8, Table 5.2.1 and row 2, Table 5.1.1). In spite of the small percentage increments in the market price of composite imports in USA (0.05) and EU (0.02), this leads to increases in private household import demands of 1.35 and 0.7 per cent in USA and EU respectively ${ }^{17}$. The much larger fall in the price of domestically sourced Stuff - 0.3 per cent in USA and 0.19 per cent in EU - causes the relative price of domestic- vis-a-vis foreign-sourced Stuff to fall by 0.35 and 0.21 per cent in USA and EU respectively. Given the expansionary effect on demand ( $q p$ ) for composite Stuff due to the general increase in consumption demand, this leads to substitution in favour of domestic Stuff in USA and EU and reinforces the expansion effect. This is reflected in increases of 2.2 and 1.2 per cent in private consumption demand for domestic Stuff in USA and EU respectively.

As opposed to this, in the case of ROW, a decline in the price of composite imports by 0.05 per cent and a rise of 0.12 per cent in the price of domestic Stuff causes the relative price of domestic Stuff to increase by 0.17 per cent. This leads to substitution in favour of imported Stuff with a relatively larger percentage increase $(0.5)$ in demand for foreign composite Stuff as compared to that in domestic Stuff (0.07). Since Armington elasticities are the same across uses and regions, similar considerations apply in the case of public consumption.

17 The share of imports by public and private sectors together in aggregate imports of tradable Stuff are 38 per cent for USA, 21 per cent for EU and 22 per cent for ROW. The rest of aggregate imports of Stuff are used as intermediate inputs by firms producing Stuff and CGDS. Firms' demand for composite Stuff as intermediate inputs also changes and this, in turn, affects changes in aggregate region-wide imports of Stuff. We do not discuss this at least for the time-being. 
The aggregate utility index $[u(r)]$ proxies regional real income ${ }^{18}$. In the model, percentage changes in the sub-utility indexes for the public $[u g(r)]$ and private $[\mathrm{up}(\mathrm{r})]$ household consumption are equal to the percentage changes in real quantities purchased by the representative government and private households respectively. The Cobb-Douglas utility function is self-dual ${ }^{19}$ as it generates an unit cost function of the same functional form as the primal. Following this property, the income deflator [incdeflator $(r)$ ] for $y(r)$ is defined as the sum over the products obtained by multiplying the CobbDouglas price indexes for each income use viz., ppriv $(r), \operatorname{pgov}(r)$ and psave with their corresponding region-wise shares in total income ${ }^{20}$. Table 5.2.3 reports the values of the shares - i.e., PRIVEXP/INCOME, GOVEXP/ INCOME, SAVE/INCOME and the incdefaltor( $r$. Row 4 in Table 5.2.3 shows that incdeflator $(r)$ preserves the same ranking, sign and order of magnitude as the ppriv and pgov (rows 17 and 18, Table 5.2.1). Subtracting row 4 of Table 5.2.3 from row 1 of Table 5.2.1, we reproduce, almost exactly, the results on real income (row 3, Table 5.2.1).

TABLE 5.2.3 Budget shares of each income use category and incdeflator ${ }^{(\mathrm{c})}$

\begin{tabular}{lccc}
\hline \multicolumn{1}{c}{ Values of: } & USA & EU & ROW \\
\hline 1. PRIVEXP/INCOME & 0.7711 & 0.7017 & 0.6926 \\
2. GOVEXP/INCOME & 0.2108 & 0.2158 & 0.1515 \\
3. QSAVE/INCOME & 0.0181 & 0.0825 & 0.1559 \\
4. incdeflator & -0.27 & -0.17 & +0.09 \\
\hline
\end{tabular}

(c) The shares are calculated from base-period data and hence these are base-case values; under the Cobb-Douglas specification, these are unchanging parameters.

In percentage change form, the first-order condition for this optimisation exercise yields: $\mathrm{u}(\mathrm{r})=[\operatorname{PRIVEXP}(\mathrm{r}) / \operatorname{INCOME}(\mathrm{r})] * \mathrm{up}(\mathrm{r})+[\operatorname{GOVEXP}(\mathrm{r}) / \operatorname{INCOME}(\mathrm{r})] * \mathrm{ug}(\mathrm{r})+$

[SAVE (r)/INCOME (r)] $*$ qsave (r)

Thus, percentage changes in real income are calculated by summing over the percentage changes in the sub-utility indexes multiplied by their corresponding shares in aggregate income.

19 The duality between production and cost function is formally analogous to the duality between utility and expenditure function - this implies that minimization of total outlay on public and private consumption and saving subject to the specified level of utility will give the same demand equations for these income uses. For a discussion on 'self-duality' between CobbDouglas production and cost function, see Varian (1984) Microeconomic Analysis, 2nd edition, pp. 62-64, 69-73.

The mathematical expression for incdeflator $(r)$ is:

incdeflator $(\mathrm{r})=[\operatorname{PRIVEXP}(\mathrm{r}) / \operatorname{INCOME}(\mathrm{r})] *$ ppriv $(\mathrm{r})+[$ GOVEXP $(\mathrm{r}) / \operatorname{INCOME}(\mathrm{r})] *$ pgov $(\mathrm{r})+[\operatorname{SAVE}(\mathrm{r}) / \mathrm{INCOME}(\mathrm{r})] *$ psave.

With PSAVE being the numeraire in the model, psave $=0$ so that the last term in the equation vanishes to yield the price index for income in general. 
Now, the GDP deflator ( $p g d p)$ is weighted sum of percentage changes in the index of the price of the domestic absorption (NA_prigne), in the export price index $(p x w)$, in the price index for exports to the international transportation sector $(\mathrm{pm})$ and in the aggregate import price index (pim) the weights being the shares in GDP of gross national expenditure (GNE), of exports (VXWD), of sales to the global transport sector (VST), and of imports (VIWS) ${ }^{21}$.

$p g d p$ includes the change in the price of exportable Stuff ( $p x w)$ with a positive weight that includes exports rather than just domestic consumption - as in the case of NA_prigne. Also, pgdp includes pim with a negative weight. Hence, the percentage increase pim and the percentage fall pxw lead to a more negative change in $p g d p$ than NA_prigne. Now, the consumption deflators include the price of imports with positive weight. These consumption deflators are included in NA_prigne and thus, it includes the import price index with a positive weight.

From Table 5.2.4, it is evident that the difference between $p g d p$ and NA_prigne clearly relates to the percentage deviation of the terms-of-trade (TOT ) from the control scenario ${ }^{22}$. The fall in TOT in USA and EU does not cause CPI, pgov and hence, NA_prigne to fall as much as $p g d p$ - see rows 1 and 5 in Table 5.2.4. This implies that a decline in TOT implies a rise in the consumption deflators (which include price of imports) relative to $p g d p$ (which includes price of exports) in these regions. Similar considerations explain relatively larger percentage changes in $p g d p$ relative to NA_prigne and the consumption deflators in case of ROW.

In our simulation, an increase in nominal income [y(r)] leads to equiproportionate increases $y p(r)$ and $y g(r)$ for any given region (as discussed in subsection 5.2.a). For USA and EU, CPI and 'pgov' do not fall as much as the GDP deflators and this results in comparatively higher

The GDP deflator, $p g d p$, can be broken down into the following components as below: pgdp=NA_prigne*(GNE/GDP)+pxw*(VXWD/GDP)+pm*(VST/GDP)-pim*(VIWS/GDP)

It is to be noted that 'pm' and 'pxw' are the same. Nominal domestic absorption, GNE(r) is expressed as: GNE(r)= PRIVEXP(r)+GOVEXP(r)+REGINV(r). Thus, the GNE deflator is: NA_prigne $(\mathrm{r})=$ ppriv $(\mathrm{r}) *[\mathrm{PRIVEXP}(\mathrm{r}) / \mathrm{GNE}(\mathrm{r})]+\operatorname{pgov}(\mathrm{r}) *[\mathrm{GOVEXP}(\mathrm{r}) / \mathrm{GNE}(\mathrm{r})]+$ $\operatorname{pcgds}(\mathrm{r}) *[\mathrm{REGINV}(\mathrm{r}) / \mathrm{GNE}(\mathrm{r})]$.

After some algebraic manipulation, we can re-write the expression in Footnote 21 as:

pgdp-NA_prigne=[pxw*\{(VXWD+VST)/GNE $\}]-[$ pim*(VIWS/GNE $)]-$ pgdp*(TradeBalance /GNE)]

In the case of balanced trade, VXWD+VST=VXW=VIWS, this equation becomes:

pgdp-NA_prigne $=($ VIWS/GNE $)($ pxw - pim $)$. Also, in case of balanced trade, GNE $(r)=$ GDP $(r)$. Thus, multiplying both sides of the above expression by [GNE/GDP], we rewrite it as:

pgdp-NA_prigne $=[\mathrm{pxw}-\mathrm{pim}] *[\mathrm{VIWS} / \mathrm{GDP}]=[\mathrm{VXW} / \mathrm{GDP}] *[\mathrm{pxw}-\mathrm{pim}]$

The variable (pxw - pim), the percentage change in the ratio of export prices to import prices, is a conventional measure of the change in the terms-of-trade. Although the GTAP standard TOT definition also includes the price of the non-traded regional investment goods, QO(CGDS, r), here we use the more conventional definition introduced above. 
TABLE 5.2.4 Component-wise effects on pgdp ${ }^{(f)}$

\begin{tabular}{|c|c|c|c|}
\hline Share weighted values of: & $U S A$ & $E U$ & $R O W$ \\
\hline 1. GNE deflator [=NA_prigne* GNE/GDP] & -0.278 & -0.180 & +0.101 \\
\hline 2. Price of exports $[=\mathrm{pxw} \times$ Exports/GDP $]$ & -0.029 & -0.020 & +0.025 \\
\hline 3. Price of imports $[=\operatorname{pim} \times$ Imports/GDP $]$ & +0.005 & +0.002 & -0.010 \\
\hline $\begin{array}{l}\text { 4. Price of exports for global transportation } \\
\text { sector }[=\mathrm{pm} \times \mathrm{VST} / \mathrm{GDP}]\end{array}$ & -0.001 & -0.003 & +0.001 \\
\hline $\begin{array}{l}\text { 5. Percentage changes in GDP price deflator } \\
{[\operatorname{pgdp}=(1)+(2)+(4)-(3)]}\end{array}$ & -0.313 & -0.205 & +0.137 \\
\hline
\end{tabular}

(f) Calculated from base-period data. Figures in row 5 match the figures in row 2 in Table 5.2.1 when we do 'rounding' to 2 decimal places.

percentage increases in real consumption than in real GDP. In the case of ROW, relatively smaller percentage increases in the consumption deflators than in $p g d p$ cause the percentage change in real consumption to be higher than in real GDP (row 5, 8 and 19 in Table 5.2.1).

In the base-case, for both USA and EU, nominal GNE exceeds GDP (and hence, each has an initial trade deficit) whereas in ROW, GDP outweighs GNE (and hence, ROW has initial trade surplus). However, despite moving in the same direction in every region, real GNE [NA_realgne $(r)]$ diverges from real GDP $[q g d p(r)]$ - compare rows 9 and 19 in 5.2.1 ${ }^{23}$. GNE includes gross investment expenditure - the value of

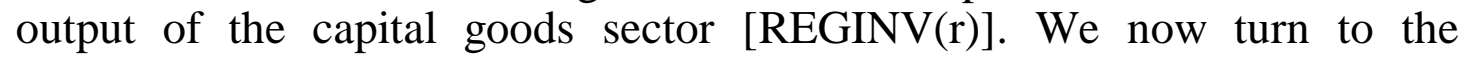
explanation of why the investment results look the way they do.

We can write in nominal terms,

GDP $(r)=$ GNE (r) + TBAL (r) where TBAL (r) is the regional trade balance. Thus, in percentage change form we get

$\operatorname{gdp}(\mathrm{r})=$ gne $(\mathrm{r}) *$ [GNE (r)/ GDP (r)] + DTBAL (r)/GDP (r) where DTBAL is the ordinary change in TBAL.

Using the expression for [pgdp -NA_prigne] when TBAL $\neq 0$ [as in Footnote 23] and the expression for $g d p(r)$ as derived above, algebraic manipulation yields, for any region, the difference between $q g d p$ and NA_realgne as:

$$
\begin{array}{r}
\text { qgdp - NA_realgne }=\text { DTBAL/GDP }-[\text { TBAL/GDP }] * \text { NA_realgne }- \\
{[\text { pxw } *(\text { VXW/GDP })-\text { pim } *(\text { VIWS/GDP })]}
\end{array}
$$

When TBAL $=0$, i.e., there is balanced trade so that VXW $=$ VIWS, DTBAL $=0$, the above difference can be written as:

qgdp - NA_realgne $=-[$ VIWS/GDP $] *(\mathrm{pxw}-\mathrm{pim})$. Thus, the differential between $q g d p$ and realgne is ascribed to changes in TOT and relevant trade share/s. 


\section{2.b Regional Effect of investment allocation mechanism ${ }^{\S}$}

The increase in $p v a$ and each of its components by the same percentage leads to an increase in the rental or supply price of capital as an input into production in every region by the same magnitude as ' $p v a$ ' - compare row 3 in Table 5.2.5 with row 7 in Table 5.1.1.

TABLE 5.2.5 Simulated effects on rate of returns and base-period values of some coefficients ${ }^{(f)}$

\begin{tabular}{|l|c|c|c|}
\hline \multicolumn{1}{|c|}{ Values of: } & USA & $E U$ & ROW \\
\hline 1. GRNETRATIO [r] & 1.516 & 1.607 & 1.447 \\
\hline 2. INVKERATIO [r] & 0.048 & 0.064 & 0.079 \\
\hline 3. Per cent changes in Rental price of capital [ps(Capital,r)] & 1.68 & 0.86 & 0.19 \\
\hline 4.Per cent changes in Price of CGDS [ps(CGDS,r) = pcgds (r)] & -0.26 & -0.17 & +0.09 \\
\hline 5. Per cent changes in Current nett rate of return [rorc(r)] & 2.94 & 1.66 & 0.14 \\
\hline 6. Per cent changes in Expected nett rate of return [rore(r)] & 2.90 & 1.54 & -0.06 \\
\hline 7. Per cent changes in End of period capital stock [ke(r)] & 0.004 & 0.012 & 0.02 \\
\hline
\end{tabular}

(f) The figures in this Table are rounded to 2 or, 3 decimal places. Values for the coefficients are reported from base period data.

With PSAVE being the numeraire in the model (as in the base-case), the price of the global saving good is unaltered in any simulation. As explained in subsection 5.2.a, the increases in $y(r)$ lead to equal percentage increases in the corresponding regional demands for nett savings, qsave (nominal and real) which are aggregated into a global nett saving pool so that the global supply of saving - used to finance global expenditure on nett investment - increases following the shock. The percentage increase in the global supply of capital goods composite [ globalcgds] is a weighted average of qsave (row 4, Table 5.2.1) ${ }^{24}$.

As all other markets are in equilibrium (which is checked by inspecting the updated post-simulation data-base), the market for the 'saving' commodity must clear à la Walràs' Law. We checked that the

$\S \quad$ Space limitations prevent us from reporting all the calculations in this section. As has been mentioned elsewhere, since CGDS is non-traded and investment is not available online for production in the solution period, the investment allocation mechanism does not enrich the story associated with the technology transmission via trade. This consideration made us parsimonious while drafting this section. However, interested readers can contact the author for an unabridged version of this particular section named "Elaboration of investment allocation mechanism".

24 The formula used for this calculation is: globalcgds $=\sum_{\mathrm{r}}$ [SAVE(r)/GLOBINV] $*$ qsave $(r)$. The values for these shares in the base case are $0.048,0.242$ and 0.71 for USA, EU and ROW respectively. 
endogenous walraslack variable is zero to ensure market-clearing in the omitted market and post-shock equilibrium in the global economy.

Since the portfolio of regional nett saving commodities provides a composite investible fund, the increase globalcgds [三 walras_sup] in the omitted market translates into a matching change in global nett saving demand [walras_dem] as well in that market. In this closure, as the world pool of the real CGDS composite is distributed across regions in the same fixed proportion ${ }^{25}$ of NETINV(r) to GLOBINV as in the base-case, because of its higher base-period proportion, ROW gets a larger allocation (67 per cent) from the global nett saving pool than USA ( 7 per cent), while EU receives the remainder (26 per cent).

Given the fixity of the regional composition of global nett investment, the region-specific ratios of NETINV(r) to the GLOBINV pool are (in the solution period) unchanged from the base case, so the percentage changes in regional real nett investment demand are equal to globalcgds i.e., 0.48 per cent. Regional demand for real gross domestic capital formation [ $q c g d s(r)]$ is determined by multiplying a region-specific ratio of conversion from nett to gross investment ${ }^{26}$. Thus, the allocation mechanism causes real gross investment demand in ROW to increase by a higher percentage than in USA and EU, leading to a surge in GNE relative to GDP in ROW.

In the control scenario, USA and EU had trade account deficits and ROW had a trade surplus. According to the TFP shock-induced mechanism, USA and EU are able to reduce their trade and saving deficits, whereas ROW sees a fall in its surpluses (compare Tables 5.2.6a with 5.2.6b). Whilst ROW receives a higher allocation of globalcgds than USA and EU, the percentage increase in saving in ROW, (qsave) is less than that in USA and EU (see row 4, Table 5.2.1). This follows from the fixed budget-share of regional saving in regional income under the Cobb-Douglas specification. However, a fall in the level of gross investment in USA as opposed to a relatively large rise in the level of gross saving has caused a reduction in the saving gap there. In the case of EU, a modest rise in gross saving coupled with a very weak rise in gross investment has managed to reduce the saving gap in this region also (compare rows 3, Tables 5.2.6a and 5.2.6b). As there has

Here the proportion refers to the base-case values of a region-specific ratioNETINV(r)/GLOBINV, where GLOBINV $=\sum_{r}$ NETINV (r) and NETINV (r) is regional nett investment. These ratios differ from the corresponding regional shares of the global capital stock in the data-base. There is nothing to ensure that the region-wise beginning of period capital stock to global capital stock ratio is kept constant during a simulation. Consequently, the ratio applied here must be interpreted strictly in terms of region-wise fixed nett investment flows.

The values for the 'proportion' of NETINV(r) to REGINV(r) calculated as per the base-case data are respectively $0.176,0.389$ and 0.514 for USA, EU and ROW. The increase $q c g d s(r)$ is this ratio times the percentage deviation (0.48) of regional nett investment demand from the base-case. 
TABLE 5.2.6a Base-case values of Gross Saving and Gross Investment ${ }^{(\sim)}$

\begin{tabular}{|l|c|c|c|c|}
\hline \multicolumn{1}{|c|}{ Base-case values of: } & USA & EU & ROW & $\begin{array}{c}\text { SUM } \\
\text { over } \\
\text { rows }\end{array}$ \\
\hline 1. Gross Saving & 737401.9 & 1304481.97 & 2679526.5 & - \\
\hline 2. Gross Investment [REGINV(r)] & 779940 & 1343140 & 2598330 & - \\
\hline 3. Saving Gap [ (1) - (2) ] & -42538 & -38658 & +81196 & 0.00 \\
\hline 4. Trade balance (in million U.S. \$) & -42538 & -38656 & +81200 & 6.00 \\
\hline
\end{tabular}

( ) Calculated from base-period data by adding the depreciation figures to net saving and investment figures.

TABLE 5.2.6b Post-shock values of Gross Saving and Gross Investment ${ }^{(!)}$

\begin{tabular}{|l|c|c|c|c|}
\hline \multicolumn{1}{|c|}{ Simulated values of: } & USA & EU & ROW & $\begin{array}{c}\text { SUM } \\
\text { over } \\
\text { rows }\end{array}$ \\
\hline 1. Gross Saving & 737557.33 & 1307913.4 & 2683641.3 & - \\
\hline 2. Gross Investment & 778587.87 & 1343336.94 & 2607190 & - \\
\hline 3. Saving Gap [ (1) - (2) ] & -41030.5 & -35423.5 & +76451.3 & -2.70 \\
\hline 4. Trade balance (in million U.S. \$) & -41029 & -35423 & +76450 & -2.00 \\
\hline
\end{tabular}

(!) Based on the post-solution data using the same procedure as in case of Table 5.2.8a.

been a higher percentage increase in the value of exports than in the value of imports in both USA and EU, the trade deficits in these two regions are reduced. These improvements in trade balances are equal to the differences between row 4 of Table 5.2.6b and the same row in Table 5.2.6a; they account for the 'reduced' saving deficits in USA and EU so that the declines in the trade deficits almost exactly match the reductions in the saving gaps.

As is evident from Tables 5.2.6a and 5.2.6b, ROW initially had a 'saving surplus' to lend investible funds to USA and EU. After the shock, ROW is still a nett external creditor to USA and EU, although not as strongly so as previously. We see that ROW's surplus has declined by US \$ 4744.7 million. However, the TFP shock causes the value of imports of Stuff in ROW to rise by a larger proportion $(0.403$ per cent) than that of its exports ( 0.16 per cent). This is associated with a fall of US $\$ 4750$ million in the trade surplus in ROW (compare rows 4, Tables 5.2.6a and 5.2.6b).

Not having generated adequate domestic saving for meeting its relatively large gross investment demand, ROW must finance the gap by capital inflow, which shows up here as a fall in its trade surplus. This is matched by the sum of the improvements in the trade balances of USA and 
EU (the sources of the capital inflows) ${ }^{27}$. In the solution period, the sum over regions of the differences between gross regional saving and investment [regional savings gap] equals zero (excepting the discrepancy due to the rounding errors) as does the sum of the regional trade balances ${ }^{28}$.

In this closure, regional capital stocks in use are kept at their control equilibrium values [fixed capital stocks $(\mathrm{KB}(\mathrm{r}))$ ].With full capacity utilization, the percentage changes in the flow of capital services, ksvces $(r)$, from these stocks, also remain unchanged. ${ }^{29}$ As the percentage change in $\mathrm{KE}(\mathrm{r})^{30}$ depends on the change in real gross investment flows in a region and on the base-period value of INVKERATIO(r) - the ratio of gross regional investment [REGINV(r)] to [ KE(r) ] - higher values of INVKERATIO(r) and $q c g d s(r)$ in ROW are reflected in relatively larger percentage changes in its end-of-period capital stock as compared to that in EU and USA (row 7, Table 5.2.5).

Assumption of identical sensitivity of the prospective rate of return (for the period following the solution period) to the prospective proportional expansion in the regional capital stock across all regions implies that a relatively larger percentage increase in $\mathrm{KE}(\mathrm{r})$ and a smaller value of current rates of return $\operatorname{rorc}(r)^{31}$ in ROW cause rore $(r)$ to fall there. ${ }^{32}$ On the other hand, a relatively larger $\operatorname{rorc}(r)$ and very small percentage increases in KE $(r)$ in USA and EU causes rore( $r$ ) to increase in the period following the solution period in these two regions (row 6, Table 5.2.5). ${ }^{33}$

In GTAP, there is no option for meeting the current account deficit by 'equity investment flow' mechanism. The only way to meet the 'gap' is by incurring new debts from overseas.

Since for each region, Gross Save (r)- REGINV (r)= VXW (r)-VIW (r), for the global economy as a whole to be in equilibrium, $\sum_{\mathrm{r}}\left[\right.$ Gross Save (r)- REGINV (r)]= $\sum_{\mathrm{r}}[\mathrm{VXW}(\mathrm{r})-$ $\operatorname{VIW}(\mathrm{r})]=0$.

Here, fixing aggregate capital stock exogenously means flow of services from that stock in the solution period, $\operatorname{ksvces}(\mathrm{r})=0$.

In levels form, the stock-flow relation for $\mathrm{KE}(\mathrm{r})$ and $\mathrm{KB}(\mathrm{r})$ is: $\mathrm{KE}(\mathrm{r})=\mathrm{KB}(\mathrm{r}) *[1-\mathrm{DEP}(\mathrm{r})]+\operatorname{REGINV}(\mathrm{r})$. Corresponding percentage change form is given by:

$\operatorname{ke}(\mathrm{r})=\operatorname{INVKERATIO}(\mathrm{r}) *$ qcgds $(\mathrm{r})+\mathrm{kb}(\mathrm{r}) *$ [1- INVKERATIO $(\mathrm{r})]$. When $\mathrm{kb}(\mathrm{r})=0, \mathrm{ke}(\mathrm{r})$ is endogenously determined by changes in gross real regional investment - qcgds(r).

In level form, rorc $(r)$ is expressed as: $\operatorname{RORC}(r)=[\operatorname{RENTAL}(r) / P C G D S(r)]-V D E P(r)$. The corresponding percentage change form is: $\operatorname{rorc}(\mathrm{r})=$ GRNETRATIO $(\mathrm{r}) *$ [rental $(\mathrm{r})$-pcgds $(\mathrm{r})]$ where GRNETRATIO (r) is the ratio of the gross to the nett rate of return in region $r$.

32 In levels form, prospective rate of return is: $\operatorname{RORE}(\mathrm{r})=\operatorname{RORC}(\mathrm{r}) *[\mathrm{KE}(\mathrm{r}) / \mathrm{KB}(\mathrm{r})]^{-\operatorname{RORFLEX}(\mathrm{r})}$ where RORFLEX $(r)=10$ is a parameter-for explanation, see Section 4.2 above.

The corresponding percentage change form is: rore $(r)=\operatorname{rorc}(r)-\operatorname{RORFLEX}(r) *[k e(r)-k b(r)]$

$=\operatorname{rorc}(\mathrm{r})-\mathrm{RORFLEX}(\mathrm{r}) *[\operatorname{INVKERATIO}(\mathrm{r}) * \mathrm{qcgds}(\mathrm{r})-\quad \mathrm{kb}(\mathrm{r}) * \operatorname{INVKERATIO}(\mathrm{r})]$. With $\mathrm{kb}(\mathrm{r})=0$ and given INVKERATIO(r), rore(r) depends on rorc(r) and qcgds(r).

33 Note that these changes are percentage, not percentage-point, changes in expected rates of return. 


\section{2.c Regional composition of international trade}

Due to the Armington specification of commodity substitution, even in a world with one generic traded-commodity in every region, the relative price divergences (between the three varieties of Stuff) across regions (after the TFP shock) induce changes in regional TOT and open up the scope for interregional competition via trade. Consequently, these lead to changes in the regional composition of exports and imports depending, inter alia, on the movements in TOT.

Looking at the global economy as a whole, we observe that after the shock there has been an increase in the quantity index of global merchandise exports and imports of Armington substitutable Stuffs by 0.57 per cent ${ }^{34}$. However, ROW experiences a small percentage rise in the price of domestically produced Stuff as compared to relatively large percentage falls in the prices of Stuff exported by USA and EU (as explained in subsections 5.1 and 5.2.a). Thus, the price index of global merchandise exports of Stuff [pxwcom(Stuff)] falls by 0.02 per cent. ${ }^{35}$ Similar considerations explain the percentage fall in the index of world prices of total supplies of Stuff $[p w$ (Stuff) $] .{ }^{36}$

Decomposition of region-specific differential TOT effects identifies the forces behind such changes. We follow the decomposition à la McDougall (1993) ${ }^{37}$ where the percentage change in regional terms of trade $[\operatorname{tot}(r)]$ is split into two components as below:

$$
\operatorname{tot}(r)=p x(\bullet, r)-p m(\bullet, r)
$$

where $p x(\bullet, r)$ is the percentage change in the price received for exports and $\operatorname{pm}(\bullet, r)$ is the percentage change in the price paid for imports. Suppose $\operatorname{pxw}(i, r)$ and $\operatorname{piw}(i, r)$ are respectively the percentage changes of the export and import prices of traded commodity $i$ in any region r, and EXP_SHR $(i, r)$ and IMP_SHR $(i, r)$ are respectively the export share of commodity i in total export expenditure and import share of commodity $\mathrm{i}$ in total import expenditure in any region $r$.

34 The calculation involves multiplying region-wise shares of exports of Stuff in aggregate worldwide exports (at $f o b$ prices) by the corresponding percentage increases in regional aggregate volume of exports of Stuff and summation over the products thus obtained. ROW has a higher share (62 per cent) in total world exports of Stuff than USA (17 per cent) and EU (21 per cent). Thus, $0.57=(1.71 \times 0.17)+(1.19 \times 0.21)+(0.05 \times 0.62)$.

This is calculated as: $(0.17 \times-0.30)+(0.21 \times-0.19)+(0.62 \times 0.12)]$. The price index of world trade [pxwwld] falls by 0.02 per cent as well (similar calculations are involved).

The base-case shares of value of output of Stuff of each region at world prices ( $f o b)$ in total world supplies of Stuff are 49, 24 and 27 per cent respectively for ROW, USA and EU. Thus, the magnitude is $[(0.24 \times-0.30)+(0.27 \times-0.19)+(0.49 \times 0.12)]=-0.065$.

As noted above, we adopt the conventional definition of TOT à la McDougall (1993) as opposed to the definition used in standard GTAP theory - the reason being that the TOT definition in the latter includes the price of CGDS which is a purely non-traded sector produced and sold in the local market only. 
Thus,

and

$$
p x(\bullet, r)=\sum_{i} E X P \_S H R(i, r) p x w(i, r)
$$

$$
p m(\bullet, r)=\sum_{i} I M P \_S H R(i, r) \operatorname{piw}(i, r)
$$

Then the above expression for region r's terms of trade can be written as:

$$
\operatorname{tot}(r)=\sum_{i} \operatorname{EXP} S H R(i, r) p x w(i, r)-\sum_{i} I M P \_S H R(i, r) p i w(i, r)
$$

With further manipulation following McDougall (1993), this expression yields:

$$
\begin{aligned}
\operatorname{tot}(r) & =\sum_{i}\left(E X P_{-} S H R(i, r)-I M P_{-} S H R(i, r)\right)(p w(i)-p x w w l d) \\
& +\sum_{i} E X P_{-} S H R(i, r)(p x w(i, r)-p w(i)) \\
& -\sum_{i} I M P_{-} S H R(i, r)(p i w(i, r)-p w(i))
\end{aligned}
$$

where $p w(i)$ is the world price index for total supplies of good $\mathrm{i}$ and pxwwld is the price index of world trade (average of world prices of merchandise exports). The first term on the right of (5.2.3), Wpe, captures the world price effect, whilst the last two terms show the export price effect (Xpe) and the import price effect (Mpe) respectively.

Wpe shows that if the world price of commodity i falls/rises relative to the average of all world commodity prices [i.e., $p w(i) \neq p x w w l d]$, then, depending on the sign of the regional nett trade share of good $i$, the direction of movement of regional TOT will be determined. If $r$ is a nett exporter of $i$, and the world price of $\mathrm{i}$ in general (i.e., averaged over the sources) inflates relative to all prices, then, ceteris paribus, this is good for region $\mathrm{r}$.

Xpe shows that if in any region, the exporters' price of good i falls relative to the world price of $\mathrm{i}[$ i.e., $p w(i) \neq p x w(i, r)$ ], then TOT will deteriorate. Besides the size of the shock, the extent of changes in such relativities [measured by $(\operatorname{pxw}(i, r)-p w(i))]$ reflect the degree of product diversification in the market for i (à la Armington assumption). With low Armington elasticities, ceteris paribus, the spread between the two prices will tend to be larger. By contrast, with a very large substitution elasticity, the absolute difference between $p x w(i, r)$ and $p w(i)$ tends to be smaller so that they are almost equal. If there is erosion of competitiveness following a 
shock, the large Armington elasticity coupled with the loss in competitive edge can lead to big loss of export shares of a region and consequently, can have adverse effect on TOT. That is, there may be a large fall in EXP_SHR(i,r) - IMP_SHR(i,r) between the base case and the post-shock solution.

Mpe captures the effect of divergences [ $p i w(i, r)-p w(i)]$ between the region-specific import price of good $i$ and the world price of $i$ : it shows that if the latter rises more than the former, then TOT will improve if there are no offsetting changes in Wpe and Xpe.

In a one-traded-commodity world, since EXP_SHR(Stuff, $r$ ) is identical to IMP_SHR(Stuff, $r$ ) and both are equal to unity, the first term on the right of Equation (5.2.3) for tot $(r)$ vanishes, so that this expression simplifies to the following:

$$
\operatorname{tot}(r)=p x w(\text { stuff, } r)-p i w(\text { stuff, } r)
$$

Thus, in Table 5.2.7, Wpe is zero across all regions. The intuition behind this result is that Wpe is meant to capture inter-generic-commodity competition, of which there is none in this one-commodity version of GTAP.

Since the share of Stuff in every region's exports is unity, Xpe shows in its entirety the effect of changes in the export supply price of Stuff in a region relative to an index of the average world price of Stuff. Analogously, Mpe totally captures the effect of changes in the region-specific import demand price relative to the world price.

TABLE 5.2.7 Decomposition of percentage changes in regional TOT*

\begin{tabular}{|c|c|c|c|c|}
\hline $\begin{array}{l}\text { GTAP } \\
\text { Region }\end{array}$ & $\begin{array}{l}\text { World } \\
\text { price } \\
\text { effect } \\
(W p e) \\
(1)\end{array}$ & $\begin{array}{l}\text { Export } \\
\text { price } \\
\text { effect } \\
(X p e) \\
(2)\end{array}$ & $\begin{array}{c}\text { Import } \\
\text { price } \\
\text { effect } \\
(\text { Mpe }) \\
(3)\end{array}$ & $\begin{array}{c}\text { Total TOT } \\
\text { effect [tot }(r)] \\
(1)+(2)-(3) \\
(4)\end{array}$ \\
\hline USA & 0.00 & -0.23 & +0.12 & -0.35 \\
\hline EU & 0.00 & -0.12 & +0.09 & -0.21 \\
\hline ROW & 0.00 & +0.18 & +0.01 & +0.17 \\
\hline
\end{tabular}

* We have rounded percentage changes to 2 decimal places.

Table 5.2.7 shows that in all three regions, Xpe is the most important source of the change in TOT. The changes in regional export volumes can be ascribed to two-fold movements: along the export demand schedule and shifts of the demand curve. 
As the individual regions as exporters of Stuff face downward sloping foreign demand curves for their region-specific Stuffs, a fall in the price of exports in USA and EU (as opposed to a rise in the case of ROW) is consistent with percentage rises in exports from USA and EU which are larger than the percentage expansion of exports from ROW to both of these regions - see row 14 in Table 5.2.1. In part, this has been caused by the movements along the export demand curve governed by the changes in price relativities between regions. Now, the expansion in activity level (i.e., increase in regional aggregate import demand) in each region results in outward shifts of the regional export demand curves. These changed trading conditions entail allocation of demand for aggregate composite imports of Stuff by a region across different sources of imports depending on relative price changes. Given the expansionary effect on demand for all imports of Stuff [qim(stuff, $r$ ) ] by any region $r$ due to the increase in intermediate input demand for it by firms producing Stuff and CGDS as well as that in final demand by the public and private sectors (explained before in subsection 5.2.a), changes in relativities between the price of imported Stuff from any source $\mathrm{k}(p m s(\operatorname{stuff}, k, r))$ and the aggregate import price index (pim(stuff, $r)$ ) confronting $\mathrm{r}$ determine changes in source-specific import demand by any region.

As products are differentiated by origin, divergences between the export price for Stuff produced in any region and the average world price for Stuff have given rise to changes in TOT. Taking any region $r$ as the destination of exports of Stuff from two sources viz., $\mathrm{s}$ and $\mathrm{k}$, given the Armington elasticity, the expansionary effect on aggregate imports of Stuff (qim(stuff, $r)$ ) and the import share of $\mathrm{k}$ in aggregate imports of $\mathrm{r}$, then import of Stuff from $\mathrm{s}$ to $\mathrm{r}[q x s(i, s, r)]$ depends on the changes in relativities between the price of imports of Stuff from $\mathrm{k}$ vis-a-vis that from $\mathrm{s}$. We discuss the change in composition of bilateral export sales which is contingent on these shock-induced relative price effects.

Aggregate imports into the USA increase by 1.0108 per cent. In USA, the market shares of EU and ROW in aggregate imports of tradable Stuff are 18 and 82 per cent respectively. A relatively large decline ( 0.183 per cent) in the price of imported Stuff from EU to USA as compared to a rise (0.104 per cent) in case of imports from ROW to USA causes a 2.2 per cent increase in imports of Stuff in USA from EU, whereas imports from ROW to USA rise by 0.75 per cent only. Given identical Armington elasticities across all regions (all equal to 5), this translates into an increase in demand for Stuff

In GTAP, we assume that imports of region $r$ from region $s$ are exactly the same as the exports of region s to $r$. Hence, the percentage change in demand for exports of ' $i$ ' from $s$ to $r$ can be expressed as:

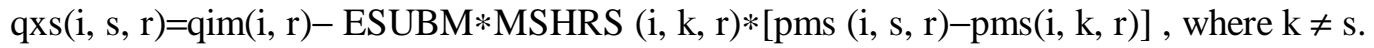
where MSHRS (i, $k, r$ ) is the share of imports from $k$ to $r$ in aggregate imports from both $k$ and $s$ to $r$ and ESUBM ( $=5$ in the database) is the Armington elasticity for imports from sources $\mathrm{k}$ and $\mathrm{s}$. Thus, we can write MSHRS (i, k, r)+ MSHRS (i, s, r) $=1$. 
from EU even though initially EU has a lower export share in USA than ROW $^{39}$.

In the case of EU, aggregate imports increase by 0.4951 per cent, while the market shares of USA and ROW in total imports are 20 and 80 per cent respectively. The decline in ' $p m s$ ' for USA ( 0.29 per cent $)$ as opposed to an increase $(0.1$ per cent) in case of ROW translates into a relatively larger increase of exports from USA (2.1 per cent) to EU than in case of ROW $(0.10 \text { per cent })^{40}$.

In its own market, ROW (a composite region) supplies 52 per cent of its total import demand whereas USA and EU supply 22 and 26 per cent respectively ${ }^{41}$. USA and EU export respectively 73 per cent and 83 per cent of their total bilateral exports (i.e., excluding exports to the global transportation sector) to ROW whereas for ROW the intra-regional export is $49 \%$. In ROW, USA faces competition from composite region ROW itself (supplying 52\% of total imports) and EU (supplying 26\% of its imports). In the post-simulation scenario, ROW experiences a rise in the market price of Stuff by $0.12 \%$. The rise in the price of imports of composite Stuff from its own constituent regions is $0.103 \%$. USA as the source of innovation experiences the maximum fall in the relative price of its Stuff after the HNTP shock. Now, the price of imported Stuff from USA to ROW fell by 0.283 per cent whereas it fell by 0.183 per cent in case of imports from EU. This led to a relatively larger percentage increase in export sales from USA to ROW (1.6) as compared to that in export sales from EU to ROW (1.1). On the other hand, the rise in the price of intra-regional imports from constituent regions by $0.103 \%$ causes a decline in intra-regional exports in ROW by 0.33 per cent ${ }^{42}$. Table 5.2.8 displays all these figures for percentage changes in bilateral export sales.

The calculations are: for EU as the source,

$2.2=1.0108-5 \times 0.82 \times[-0.183-(+0.104)] ;$ for $R O W$ as the source,

$0.75=1.0108-5 \times 0.18 \times[0.104-(-0.183)]$

40

41

42

These computations are: for USA as the source, $2.055=0.4951-5 \times 0.80 \times[-0.29-(+0.10)]$; for $R O W$ as the source, $0.10=0.4951-5 \times 0.20 \times[0.10-(-0.29)]$.

1 For ROW as composite region supplying in its own market, the equation in Footnote 37 can be modified as below:

qxs $(i, s, r)=$ qim(i, r)-ESUBM*MSHRS $(i, k, r) *[p m s(i, s, r)-p m s(i, k, r)]$

$-\operatorname{ESUBM} * \operatorname{MSHRS}(i, j, r) *[p m s(i, s, r)-\operatorname{pms}(i, j, r)]$ where $s \neq j \neq k$ are different sources of exports to destination $\mathrm{r}$.

In case of intra-regional exports, $r=s$, say, then the above equation can be expressed as: qxs $(i, r, r)=$ qim(i, r)-ESUBM $* \operatorname{MSHRS}(\mathrm{i}, \mathrm{k}, \mathrm{r}) *$ [pms $(\mathrm{i}, \mathrm{r}, \mathrm{r})-\mathrm{pms}(\mathrm{i}, \mathrm{k}, \mathrm{r})]$

$-\operatorname{ESUBM} * \operatorname{MSHRS}(\mathrm{i}, \mathrm{j}, \mathrm{r}) *[$ pms $(\mathrm{i}, \mathrm{r}, \mathrm{r})-\operatorname{pms}(\mathrm{i}, \mathrm{j}, \mathrm{r})]$ where $\mathrm{r} \neq \mathrm{j} \neq \mathrm{k}$.

These calculations are: for USA as the source, $1.588=0.462-5 \times 0.26 \times[-0.283-$ $(-0.183)]-5 \times 0.52 \times[-0.283-(+0.103)] ;$ for $E U$ as the source, $1.09=0.462-5 \times 0.22 \times[-$ $0.183-(-0.283)]-5 \times 0.52 \times[(-0.183-(+0.103)]$; for ROW as the source, $-0.33=0.462-5$ $\times 0.26 \times[0.103-(-0.183)]-5 \times 0.22 \times[0.103-(-0.283)]$. 
TABLE 5.2.8 Simulated effects on bilateral export sales

\begin{tabular}{|c|c|c|c|}
\hline \multirow{2}{*}{ To } & \multicolumn{3}{|c|}{ From } \\
\cline { 2 - 4 } & USA & EU & ROW \\
\hline USA & 0.00 & 2.05 & 1.60 \\
\hline EU & 2.20 & 0.00 & 1.09 \\
\hline ROW & 0.75 & 0.10 & -0.33 \\
\hline
\end{tabular}

Sectoral performances are described below.

\subsection{Sectoral Effects}

\section{3.a Effects on Traded Stuff Sector}

Our foregoing discussion documents that for each region, marginal productivity of 'raw' primary composite factor inputs (in conventional units), real value-added in effective units and production of Stuff go up exactly by the same percentage as the TFP improvement. Demand for real value-added measured in conventional units does not change (see row 6, Table 5.1.1). Effective price of value-added (quality-adjusted) declines in USA and EU and rises in ROW. More pronounced TFP changes lead to a more productive primary factor composite and to falling costs in USA and EU.

Stuff is produced combining the value-added composite and composite material inputs of Stuff using the Leontief technology at the top nest of the production tree (where intermediate inputs and value-added are not substitutable). Due to the expansionary effect of an increased demand, increased production of Stuff entails an equivalent increase in intermediate input demand [qf (stuff, stuff, $r$ ) ] going into its own production in each region - i.e., 2, 1.07 and $0.05 \%$ in USA, EU and ROW respectively.

The percentage falls in the price indexes for purchases of domestic Stuff as intermediate input [pfd (stuff, stuff, $r$ ) ] -0.3 per cent in USA and 0.19 per cent in EU - are relatively larger than percentage increments in price indexes of composite imports of foreign-sourced Stuff [pfm(stuff, stuff, $r$ ) ] - 0.05 in USA and 0.02 in EU. Given qf (stuff, stuff, $r$ ), the decline in relative price of domestic vis-a-vis foreign sourced Stuff -0.35 per cent in USA and 0.21 per cent in EU - leads to substitution in favour of domestic intermediate Stuff. ${ }^{43}$ Thus, the Armington structure causes a larger

43 Intermediate input demand for domestic Stuff by firms producing Stuff can be written as:

$\mathrm{qfd}=\mathrm{qf}-\mathrm{ESUBD} *[1-\mathrm{FMSHR}] *[\mathrm{pfm}-\mathrm{pfd}]$ where FMSHR is share of composite import of

Stuff going into its production. Analogously, firms' demand for imported Stuff is given by: 
percentage increase in intermediate input demand for domestic Stuff [qfd (stuff, stuff, $r$ )] i.e., 2.07 and 1.13 per cent in USA and EU respectively ${ }^{44}$. For demand for the composite import of Stuff [qfm(stuff, stuff, $r$ ) ], these are 1.19 (USA) and 0.604 (EU). ${ }^{45}$

The decline in relative price of composite imports vis-a-vis domestic Stuff by 0.17 per cent in ROW results in a 0.41 per cent increase in intermediate input demand for imported Stuff whereas intermediate input demand for domestic Stuff falls by 0.01 per cent ${ }^{46}$. In all regions domesticallysourced Stuff has a much larger share than the foreign-sourced Stuff in its production (row 3, Table 5.3.1). The supply price of Stuff depends on the pva components and price of intermediate Stuff. Now, the price of valueadded in constant efficiency units falls in USA and EU and rises in ROW (see row 9, Table 5.1.1). Also, the price of intermediate input Stuff falls in USA and EU and rises in ROW. Consequently, the zero-pure-profits equation determines that the industry price of composite tradable Stuff falls in USA and EU and rises in ROW.

TABLE 5.3.1 Simulated regional effects of technology shock on Stuff ${ }^{\circledR}$

\begin{tabular}{|l|c|c|c|}
\hline \multicolumn{1}{|c|}{ Percentage change in: } & USA & EU & ROW \\
\hline 1.Output of Stuff & 2.00 & 1.07 & 0.05 \\
\hline 2.Supply Price of Stuff & -0.30 & -0.19 & +0.12 \\
\hline 3.Share of domestically-sourced Stuff & 0.92 & 0.89 & 0.85 \\
\hline 4.Share of foreign-sourced Stuff & 0.08 & 0.11 & 0.15 \\
\hline 5.Demand for imported Stuff as an input & 1.18 & 0.59 & 0.41 \\
\hline 6. Demand for domestic Stuff as an input & 2.07 & 1.13 & -0.02 \\
\hline
\end{tabular}

@ Figures are rounded up to 2 decimal places.

\section{3.b Effects on Non-traded Capital Goods Industry}

The capital goods sector in GTAP is the one which does capital formation by assembling Stuffs from three regions and caters exclusively to the domestic market only. As mentioned before, the notion of TFP improvement is not valid here. However, as it assembles Armington substitutable Stuffs from domestic and two foreign sources, cost in this

$\mathrm{qfm}=\mathrm{qf}-\mathrm{ESUBD} *[\mathrm{FMSHR}] *[\mathrm{pfd}-\mathrm{pfm}] . \operatorname{ESUBD}(=2.5$ in the database $)$ is the Armington elasticity.

44 These are computed as: for USA, $2.068=2-2.5 \times 0.0781 \times(-0.35)$; for EU, $1.129=1.07-2.5$ $\times 0.1134 \times(-0.21)$.

45 These calculations are: for USA, $1.19=2-2.5 \times 0.922 \times(+0.35)$; for EU, $0.604=1.07-2.5 \times$ $0.8866 \times(+0.21)$.

46 These calculations are: $0.412=0.05-2.5 \times 0.8512 \times(-0.17)$; and $-0.013=0.05-2.5 \times 0.1488$ $\times(+0.17)$. 
sector is affected by the TFP improvements in the three sources of Stuff. The logic follows from our discussion in the earlier subsection. Since it is produced using Leontief technology, the percentage increase in the demand for CGDS translates into an equivalent percentage increase in the demand for Stuff as intermediate input $[q f$ (stuff, $C G D S, r)]$ - see row 6, Table 5.3.2.

TABLE 5.3.2 Simulated regional effects on capital goods industry

\begin{tabular}{lccc}
\hline \multicolumn{1}{c}{ Percentage change in: } & USA & EU & ROW \\
\hline 1. Output of CGDS [qo (CGDS, r) $=$ qcgds(r)] & 0.08 & 0.19 & 0.25 \\
2. Price of CGDS [pcgds(r) $=$ ps(CGDS, r)] & -0.26 & -0.17 & +0.09 \\
3. Rental rate/Supply price of capital (ps(Capital, r)) & 1.68 & 0.86 & 0.19 \\
4. Share of domestically-sourced Stuff & 0.89 & 0.92 & 0.87 \\
5. Share of foreign-sourced Stuff & 0.11 & 0.08 & 0.13 \\
6. Demand for composite Stuff as input into prod'n & 0.08 & 0.19 & 0.25 \\
7. Demand for imported Stuff for capital creation & -0.69 & -0.30 & +0.62 \\
\hline
\end{tabular}

$\wedge$ The figures for shares in the table are the same (when rounded up to 2 decimal places) in both the base and post-simulation data bases.

In all three regions, domestically sourced Stuff has a large share in CGDS production (row 4, Table 5.3.2). The falls in the price of domestic purchases of Stuff [pfd (stuff, CGDS, r) ] -0.3 per cent in USA and 0.19 per cent in EU [as compared to small rise in the price index for composite imports of Stuff — pfm(stuff, CGDS, $r$ ) - in USA (0.05) and EU (0.02) ] cause the relative price of domestic vis-a-vis foreign Stuff to fall in USA and EU. As opposed to this, in the case of ROW, the increase in the relative price of domestically sourced Stuff going into production of CGDS by 0.17 per cent (row 12 minus row 13, Table 5.2.1) causes substitution in favour of imported Stuff so that it increases by 0.62 per cent as opposed to a 0.2 per cent increment in intermediate input demand for domestic Stuff ${ }^{47}$.

In the case of CGDS, supply price depends on the price of intermediate input Stuff only. Since the zero-pure-profit condition requires that the price of investment goods is a weighted sum of prices of intermediate-input Stuff from the three different sources going into its production, the decline in the prices of domestically sourced Stuff in USA and EU leads to a fall in the cost of production of CGDS (row 2, Table 5.3.2). For ROW, the increase in the relative price of domestically sourced Stuff leads to an increase in the price of the investment good despite the fall in the price of composite imports. The

Similar calculations as shown in subsection 5.3.a yield the above numbers. 
increases in production of CGDS in all three regions match the corresponding increases in the demand for capital creation in every region $[q \operatorname{cgds}(r)]$.

\section{Summary and Conclusion}

In this paper, embodied technology spillovers through bilateral trade linkages have been analyzed within the GTAP framework. The analysis is embedded in a setup where each region produces a traded Stuff along with a non-traded capital good. However, the Armington assumption of product differentiation by origin opens the scope for international trade in the sourcespecific Stuff. Embodied technology spillover occurs via bilateral trade in Stuff between source (viz., USA) and destination (viz., EU and ROW). Absorption capacity (AC) and structural congruence (SS) jointly determine a capture-parameter which, together with the trade volume, endogenize the spillover coefficient.

We considered an exogenous $2 \%$ value-added augmenting TFP shock in the source country USA. Following the shock, the higher value of the capture parameter in EU allows this region to realise a high percentage of the potential productivity improvement, whereas ROW experiences a relatively less pronounced TFP improvement despite a larger proportional stimulus in imports from USA than that from EU.

In the GTAP's standard medium-run closure, the regional composition of global nett investment is unaltered by the shock and capital stock in use is also unchanged. Given this closure, the shock generates relative price divergences and consequent inter-regional competition effects. A changing composition of demand in the private and public sector and of the sectors producing Stuff and capital goods shape the profile of aggregate demand. The TFP shock leads to an increase in the marginal productivity (in conventional units) of the 'raw' primary factor composite in all three regions whilst the effective price of value-added (quality-adjusted) declines in USA and EU. Owing to the Armington structure and identical Armington elasticities across uses and regions, the relatively larger percentage falls in the price indexes for the purchases of domestically sourced Stuff as compared to the percentage rises in the price indexes of composite imports of foreign-sourced Stuff, resulted in substitution in favour of domestic Stuff in USA and EU. On the other hand, the decline in the relative price of foreign composite imports and an increase in the price of domestic Stuff in ROW causes substitution in favour of imported Stuff. Given the expansionary effects due to increased general activity levels, changes in the price relativities between regions alter the trading conditions.

Divergences between the export supply price of Stuff in the regions and its average world price have led to changes in regional terms of trade. Thus, the rise in the price of Stuff in ROW erodes its competitive edge in the global market for Stuff. In particular, a decline in the price of exports in USA and EU translated into a larger percentage expansion of exports from USA and 
EU to ROW than that from ROW to both of these regions. ROW loses its export share in its own market. With no scope for inter-generic-commodity competition, the terms-of-trade effect predominantly reflects the export price effect.

Given the general-equilibrium relative price effects, a higher percentage increase in the value of exports than in the value of imports in both USA and EU has caused their initial trade deficits to decline. For ROW, the TFP shock causes the value of imports to rise by a larger proportion than that of its exports leading to a fall in its initial trade surplus. Thus, trade creation between the regions is manifest as an increase in bilateral and global trade volumes. However, in the case of the composite region ROW, the loss in competitiveness has caused trade diversion and a resultant loss in the export share in its own market ${ }^{48}$.

This effect is coupled with the regional investment allocation mechanism. ROW having obtained the highest proportional allocation of the global supply of investible funds according to the base-case proportions, experiences a relatively larger increase in demand for gross domestic capital formation than that do USA and EU. Given the constant budget share in regional income, real nett savings increased by less than the real gross investment in ROW whereas the reverse is the case with USA and EU. ROW, having generated an insufficient increase in real savings to finance the new capital formation, has to depend on capital inflows from abroad manifest as an equivalent fall in its trade surplus. By contrast, USA and EU generate an improvement in their trade balances, leading to lower deficits.

The simulations in this paper are meant to be illustrative only since the size and location of the productivity shock was arbitrary, as were the numerical values of the parameters affecting absorptive capacity and structural similarity. Policy conclusions must await the moblilization of realistic data.

Under the GTAP conventions, non-zero tariffs and trade flows can exist in the diagonal positions of bilateral matrices in the case of regions which are composites of countries or of smaller regions. 


\section{REFERENCES}

Armington, P. (1969) “A Theory of Demand for Products Distinguished by Place of Production, IMF Staff Papers, No. 16, pp. 179-201.

Barro, Robert J. and Xavier Sala-I-Martin (1995), Economic Growth, New York: McGraw-Hill.

Coe, D. T. and Helpman, E. (1995), "International R\&D Spillovers", European Economic Review, No.39, pp. 859-887.

Coe, D. T. , Helpman, E. and Hoffmaister, A.W. (1997), "North-South R\&D Spillovers", The Economic Journal, No. 107, pp.134-149.

Cohen, Wesley, and Daniel Levinthal. (1990), “Absorptive Capacity: A New Perspective on Learning and Innovation", Administrative Science Quarterly, No. 35, pp. 128-52.

Connolly, Michelle P. (1997) "Technology, Trade and Growth: Some Empirical Findings", Federal Reserve Bank of New York, Research Paper, No. 9727 (September), pp.1-27.

Eaton, J., and S. Kortum (1996a) "Trade in Ideas: Patenting and Productivity in the OECD”, Journal of International Economics, No. 40, pp. 251-278.

(1996b) "International Technology Diffusion: Theory and Measurement", Boston University and NBER, Working Paper, pp. 1-56.

(1994) "International Paptenting and Technology Diffusion”, NBER, Working Paper, No. 4931 (September), pp.1-42.

Edwards, Sebastian (1997) "Openness, Productivity and Growth: What do We Really Know?", National Bureau of Economic Research (Cambridge, MA), Working Paper, No. 5978 (March), pp.1-20+Appendix.

Grossman, G. M., and E. Helpman (1991a) "Innovation and Growth in the Global Economy”, MIT Press, Cambridge.

(1991b) "Quality Ladders in the Theory of Growth", Review of Economic Studies, No. 58, pp. 43-61.

Hall, Robert E. and Charles I. Jones (1998) "Why do Some Countries Produce So Much More Output Per Worker than Others?", Working Paper, Stanford University, Version 4 (March).

Harrison, W. Jill and K.R. Pearson (1996) "Computing Solutions for Large General Equilibrium Models Using GEMPACK”, Computational Economics, Vol. 9, pp.83-127.

Hayami, Y and V.W. Ruttan (1985) Agricultural Development: An International Perspective, Baltimore and London,: The John Hopkins University Press.

Hertel, Thomas W. (ed.) (1997) Global trade Analysis: Modeling and Applications (New York and Cambridge: Cambridge University Press).

and Marinos E. Tsigas (1997) "Structure of the Standard GTAP Model", Chapter 2 in Hertel (ed.) cited above.

Horridge, J. Mark (1997) "DAGG Guide", Centre of Policy Studies, Monash University, Clayton, Melbourne.

Jones, C. I. (1995) "R\&D-based Models of Economic Growth", Journal of Political Economy, No. 103, pp. 759-784. 
Keller, Wolfgang (1997) "Trade and the Transmission of Technology", National Bureau of Economic Research (Cambridge, MA),Working Paper, No. 6113 (July), pp. 1-33+Appendix.

(1997) "Absorptive Capacity: On the Creation and Acquisition of Technology in Development", Journal of Development Economics, No. 49, pp. 199-227.

McDougall, R. A. (1993) "Two Small Extensions to SALTER", Salter Working Paper, No. 12, Industry Commission, Canberra.

Meijl, Hans van and Frank van Tongeren (1997) "Endogenous International Technology Spillovers and Biased Technical Change in Agriculture", Draft Version, Agricultural Economics Research Institute (LEI-DLO), (April), pp. $1-40$.

Nelson, Richard R. (1990) "On Technological Capabilities and their Acquisition", in R.E. Evenson and G. Ranis eds. Science and Technology, Lessons for Development Policy, Westview Special Studies in Science, Technology, and Public Policy.

Padoan, Pier Carlo. (1996) "Trade and the Accumulation and Diffusion of Knowledge", Policy Research Working Paper No. 1679 (November), World Bank, International Economics Department, International Trade Division, Washington, D.C.

Powell, A. A. and C.W. Murphy (1995) Inside A Modern Macroeconometric Model: A guide to the Murphy Model, Berlin: Springer-Verlag.

Walmsley, Terrie (1998) "Long-Run Simulations With GTAP: Illustrative Results from APEC Trade Liberalisation", Preliminary Working Paper No. IP-70 (January), Centre of Policy Studies, Monash University, Clayton, Melbourne. 


\section{APPENDIX}

In this appendix, we document the aggregation method, set definitions, parameter settings and associated files as used in the implementation of a one-sector, three-region macro model. The economic model is the one described in Hertel (ed.) (1997), with some additional equations, coefficients, and variables as described in the main text.

\section{A.1 Set Modifications}

Text file SET1BY3.TXT written in the WINGEM text editor is used in running the MODHAR program interactively to create SET1BY3.HAR file.

SET 1BY3.TXT

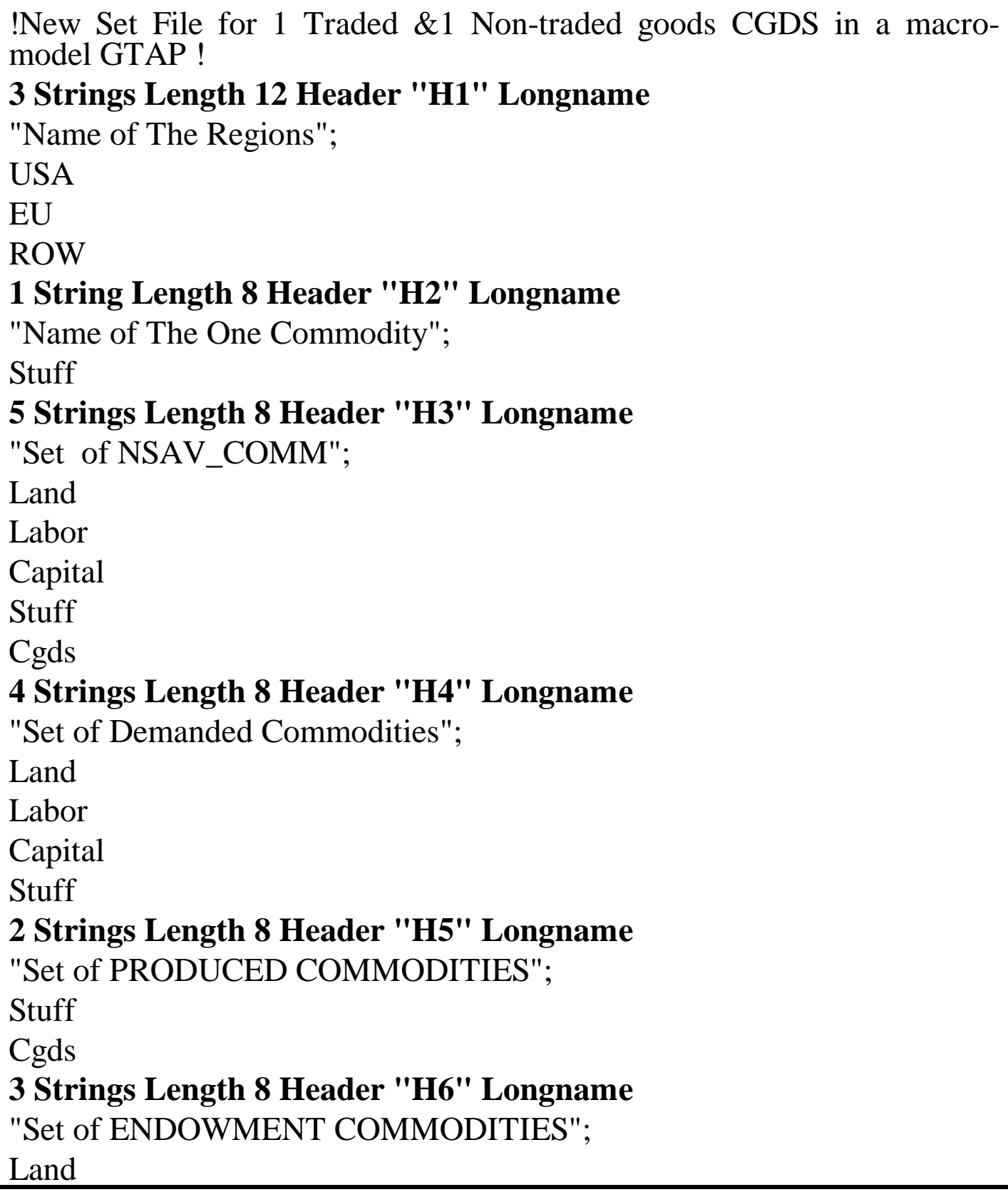




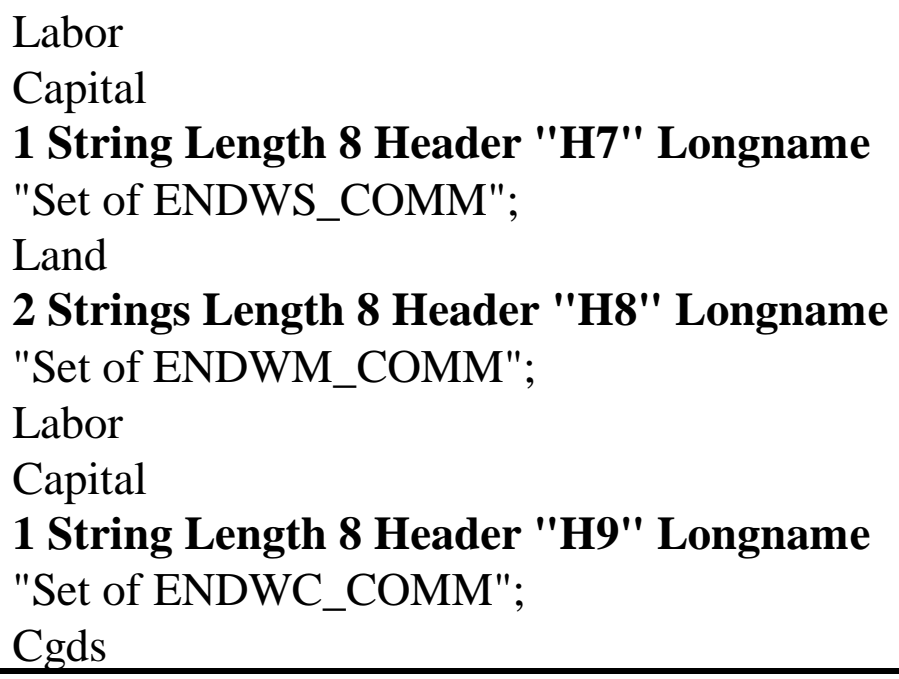

Table A.1.1 displays a list of the SETS of Regions (REG) and tradable commodity (Stuff alone), TRAD_COMM, as well as endowment commodities, ENDW_COMM, and non-tradable capital goods, CGDS_COMM. TRAD_COMM and CGDS_COMM constitute the set of produced commodities, PROD_COMM. TRAD_COMM belongs to the set of Demanded Commodities, DEMD_COMM which comprises land, labor, capital endowment commodity and Stuff. CGDS_COMM is subset of PROD_COMM and 'capital goods' does not belong to the Set DEMD_COMM. Stuff belongs to a super set containing non-savings commodities, NSAV_COMM. NSAV_COMM comprises the Sets viz., TRAD_COMM, PROD_COMM, ENDW_COMM, DEMD_COMM and the Set CGDS_COMM. ENDWS COMM is the set of sluggish factor i.e., land and ENDWM_COMM comprise the mobile factors labor and capital.

TABLE A.1.1 Definition of Regions and of Commodities in 1x3GTAP

\begin{tabular}{|l|l|}
\hline \multicolumn{1}{|c|}{ Set REG } & \multicolumn{1}{c|}{ Set NSAV_COMM } \\
\hline USA & Land, Labor, Capital [ENDW_COMM] \\
EU (European Union) & Stuff [TRAD_COMM] \\
ROW (Rest of the World) & Capital Goods [CGDS_COMM] \\
& Stuff, Capital Goods [PROD_COMM] \\
& Land, Labor, Capital, Stuff [DEMD_COMM] \\
\hline
\end{tabular}

For our purpose, three different header array (.HAR) files are created for each of the three regions as sources of invention. These files corresponding to three individual sources viz., USA, EU and ROW are 
SRCUSA.HAR, SRCEU.HAR, and SRCROW.HAR respectively. This is useful for implementing these regions as different sources of invention. These files are created by running MODHAR on a TEXT file named SETINFO.TXT describing the name of each of these regions separately. In the TABLO file, the logical file name (SETINFO) associated with these files is declared as

\begin{tabular}{l}
$\begin{array}{l}\text { FILE SETINFO \#The File containing Sources of } \\
\text { Innovations. \#; }\end{array}$ \\
\hline
\end{tabular}

By choosing the name of the header array file (.HAR) relevant for our simulation corresponding to the logical name SETINFO in the Command file (.CMF), one can implement the simulation for a specific source of invention. In the current treatment, set SRC contains USA (as the only source of innovation) and the set REG_NOT_SRC (generated directly by TABLO-see below) contains the destinations EU and ROW and therefore, we select SRCUSA.HAR as the SETINFO file in the CMF file.

Modification in the SET specifications in the TABLO file is given in TABLE A.1.2.

\section{TABLE A.1.2 Modification for set definitions in TABLO File}

SET SRC \# SOURCES OF INVENTION- Countries \#

SUBSET SRC is subset of REG

SET REG_NOT_SRC=REG-SRC

\section{A.2 Appended Variables and Equations ${ }^{\Psi}$}

The equation that has been appended and implemented in our analysis is described in the text (vide Sections 2.2b and 4.1 in the text). Apart from these, we defined the following variables and equations:

VARIABLE(All,r,REG) Tec_Chg(r);

!Value-added-share weighted Value-added Augmenting Technical change!

EQUATION E_Tec_Chg

(All,r,REG) Tec_Chg(r)=sum(j,PROD_COMM,(VA_Share(j,r)*ava(j,r)));

VARIABLE(All,r,REG)

NA_gdpfc(r)

\# Value of Nominal GDP at factor cost\#;

EQUATION E_NA_gdpfc

!Nominal value of GDP at factor cost!

(All,r,REG) Sum(i,ENDW_COMM, VOA(i,r)) * NA_gdpfc(r)

$=\operatorname{Sum}(\mathrm{i}, \mathrm{ENDW}$ _COMM,$(\operatorname{VOA}(\mathrm{i}, \mathrm{r}) *[\mathrm{qo}(\mathrm{i}, \mathrm{r})+\mathrm{ps}(\mathrm{i}, \mathrm{r})]))$;

$\Psi$

A complete list of variables including those appended are not provided here for want of space; those are available from author on request. 
EQUATION E_NA_prigdpfc

! Price index for GDP (at factor cost) by region !

(All,r,REG) Sum(i,ENDW_COMM, VOA(i,r)) * NA_prigdpfc(r) $=$ Sum $\left(\mathrm{i}, \mathrm{ENDW} \_\mathrm{COMM}, \operatorname{VOA}(\mathrm{i}, \mathrm{r}) *\left[\mathrm{ps}(\mathrm{i}, \mathrm{r})-\mathrm{Tec} \_\mathrm{Chg}(\mathrm{r})\right]\right)$;

EQUATION E_NA_realgdpfc

! Real GDP (at factor cost) by region !

(All,r,REG) Sum(i,ENDW_COMM,VOA(i,r))*NA_realgdpfc(r) $=\operatorname{Sum}\left(\mathrm{i}, \mathrm{ENDW} \_\mathrm{COMM},\left[\operatorname{VOA}(\mathrm{i}, \mathrm{r}) *\left\{\mathrm{qo}(\mathrm{i}, \mathrm{r})+\mathrm{Tec} \_\mathrm{Chg}(\mathrm{r})\right\}\right]\right)$;

VARIABLE(All,r,REG) NA_gne(r)

\# Value of GNE (at market prices) by region \#;

VARIABLE(All,r,REG) NA_realgne(r)

\#Value of Real Gross National Expenditure\#;

EQUATION E_NA_gne

!Nominal GNE at market prices by region!

(All,r,REG)

GNE(r)*NA_gne(r)=sum(i,TRAD_COMM,VGA(i,r)*[qg(i,r)+pg(i,r)])+ $\operatorname{sum}\left(\mathrm{i}, T R A D \_C O M M, V P A(i, r) *[q p(i, r)+p p(i, r)]\right)+R E G I N V(r) *[q \operatorname{cgds}(r)+p c$ $\operatorname{gds}(\mathrm{r})]$;

EQUATION E_NA_realgne

! Real GNE at market prices in Region $r$ !

(All,r,REG) NA_realgne $(r)=N A \_g n e(r)-N A \_p r i g n e(r)$;

VARIABLE (ALL,r,REG) CON_PFACy(r)

\# Contribution of primary factor payments to $\mathrm{y}(\mathrm{r}) \#$;

EQUATION E_CON_PFACy

(ALL,r,REG)

INCOME $(r) *$ CON_PFACy(r)=sum $\left(\mathrm{i}, \mathrm{ENDW} \_C O M M, \operatorname{VOA}(\mathrm{i}, \mathrm{r}) *[\mathrm{ps}(\mathrm{i}, \mathrm{r})+\right.$ qo(i,r)]);

VARIABLE (ALL,r,REG)

\# Contribution of Depreciation factor to $\mathrm{y}(\mathrm{r}) \#$;

EQUATION E_CON_DEPy

(ALL,r,REG)

$\operatorname{INCOME}(\mathrm{r}) *$ CON_DEPy $(\mathrm{r})=[\operatorname{VDEP}(\mathrm{r}) *[\operatorname{pcgds}(\mathrm{r})+\mathrm{kb}(\mathrm{r})]]$;

VARIABLE (ALL,r,REG)

CON_PHYS_DEPy(r)

\# Contribution of Physical Depreciation factor to $\mathrm{y}(\mathrm{r}) \#$;

EQUATION E_CON_PHYS_DEPy

(ALL,r,REG)

INCOME(r)*CON_PHYS_DEPy(r)=[VDEP(r) * $k b(r)]$;

VARIABLE (ALL,r,REG)

CON_VALUE_DEPy(r)

\# Contribution of REVALUATION of Capital stock to y(r)\#;

EQUATION E_CON_VALUE_DEPy

(ALL,r,REG)

INCOME $(\mathrm{r}) *$ CON_VALUE_DEPy $(\mathrm{r})=[\mathrm{VDEP}(\mathrm{r}) * \operatorname{pcgds}(\mathrm{r})]$;

VARIABLE (ALL,r,REG)

CON_TAX1y(r)

\# Contribution of TAX COMPONENT 1 to $\mathrm{y}(\mathrm{r}) \#$; 
EQUATION E_CON_TAX1y

(ALL,r,REG)

INCOME $(r) *$ CON_TAX1y $(r)=s u m\left(i, N S A V \_C O M M,\{\operatorname{VOM}(i, r) *\right.$

$[\mathrm{pm}(\mathrm{i}, \mathrm{r})+\mathrm{qo}(\mathrm{i}, \mathrm{r})]\}$ - $\{\operatorname{VOA}(\mathrm{i}, \mathrm{r}) *[\mathrm{ps}(\mathrm{i}, \mathrm{r})+\mathrm{qo}(\mathrm{i}, \mathrm{r})]\}) ;$

VARIABLE (ALL,r,REG) CON_TAX2y(r)

\# Contribution of TAX COMPONENT 2 to $y(r) \#$;

EQUATION E_CON_TAX2y

(ALL,r,REG)

INCOME $(\mathrm{r}) * \mathrm{CON} \_\mathrm{TAX} 2 \mathrm{y}(\mathrm{r})=$ sum(i,ENDWM_COMM,sum(j,PROD_COMM,\{VFA(i,j,r)*[pfe(i,j,r)+ qfe $(\mathrm{i}, \mathrm{j}, \mathrm{r})]\}$

VARIABLE (ALL,r,REG) $-\{\operatorname{VFM}(\mathrm{i}, \mathrm{j}, \mathrm{r}) *[\mathrm{pm}(\mathrm{i}, \mathrm{r})+\mathrm{qfe}(\mathrm{i}, \mathrm{j}, \mathrm{r})]\}))$;

\# Contribution of TAX COMPONENT 3 to $\mathrm{y}(\mathrm{r}) \#$;

EQUATION E_CON_TAX3y

(ALL,r,REG)

INCOME $(r) * C O N \_T A X 3 y(r)=$ sum(i,ENDWS_COMM,sum(j,PROD_COMM,\{VFA(i,j,r)*[pfe(i,j,r)+ qfe(i,j,r)] $\}-\{\operatorname{VFM}(\mathrm{i}, \mathrm{j}, \mathrm{r}) *[\operatorname{pmes}(\mathrm{i}, \mathrm{j}, \mathrm{r})+\mathrm{qfe}(\mathrm{i}, \mathrm{j}, \mathrm{r})]\}))$;

VARIABLE (ALL,r,REG) CON_TAX4y(r)

\# Contribution of TAX COMPONENT 4 to y(r)\#;

EQUATION E_CON_TAX4y

(ALL,r,REG)

INCOME $(\mathrm{r}) *$ CON_TAX4y $(\mathrm{r})=$ sum(j,PROD_COMM,sum(i,TRAD_COMM,\{VIFA(i,j,r)*[pfm(i,j,r)+qfm $(i$, $\mathrm{j}, \mathrm{r})]\}-\{\operatorname{VIFM}(\mathrm{i}, \mathrm{j}, \mathrm{r}) *[\mathrm{pim}(\mathrm{i}, \mathrm{r})+\mathrm{qfm}(\overline{\mathrm{i}}, \mathrm{j}, \mathrm{r})]\}))$;

VARIABLE (ALL,r,REG) CON_TAX5y(r)

\# Contribution of TAX COMPONENT 5 to $\mathrm{y}(\mathrm{r}) \#$;

EQUATION E_CON_TAX5y

(ALL,r,REG)

INCOME $(\mathrm{r}) *$ CON_TAX5y $(\mathrm{r})=$ sum(j,PROD_COMM,sum(i,TRAD_COMM,\{VDFA(i,j,r)*[pfd(i,j,r)+

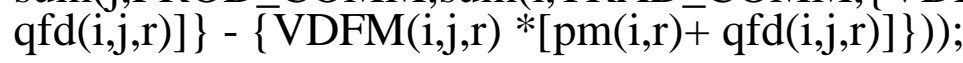

VARIABLE (ALL,r,REG) CON_TAX6y(r)

\# Contribution of TAX COMPONENT 6 to $\mathrm{y}(\mathrm{r}) \#$;

EQUATION E_CONT_TAX6y

(ALL,r,REG)

INCOME $(r) *$ CON_TAX6y $(r)=$

sum(i,TRAD_COMM, \{VIPA(i,r) * [ppm(i,r) + qpm(i,r)]\}-\{VIPM(i,r) * $[\operatorname{pim}(\mathrm{i}, \mathrm{r})+\mathrm{qpm}(\mathrm{i}, \mathrm{r})]\})$;

VARIABLE (ALL,r,REG)

CON_TAX7y(r)

\# Contribution of TAX COMPONENT 7 to $\mathrm{y}(\mathrm{r}) \#$;

EQUATION E_CON_TAX7y 
(ALL,r,REG)

INCOME $(r) *$ CON_TAX7y(r)=sum(i,TRAD_COMM, $\{$ VDPA(i,r)*[ppd(i,r)

+ qpd(i,r) $]\}-\{\operatorname{VDP} \bar{M}(\mathrm{i}, \mathrm{r}) *[\mathrm{pm}(\mathrm{i}, \mathrm{r})+\mathrm{qpd}(\mathrm{i}, \mathrm{r})]\})$;

VARIABLE (ALL,r,REG)

CON_TAX8y(r)

\# Contribution of TAX COMPONENT 8 to $\mathrm{y}(\mathrm{r}) \#$;

EQUATION E_CON_TAX8y

(ALL,r,REG)

INCOME $(\mathrm{r}) *$ CON_TAX8y $(\mathrm{r})=$

$\operatorname{sum}\left(\mathrm{i}, \mathrm{TRAD} \_\mathrm{COMM},\{\mathrm{VIGA}(\mathrm{i}, \mathrm{r}) *[\operatorname{pgm}(\mathrm{i}, \mathrm{r})+\mathrm{qgm}(\mathrm{i}, \mathrm{r})]\}\right.$

- $\{\operatorname{VIGM}(\mathrm{i}, \mathrm{r}) *[\operatorname{pim}(\mathrm{i}, \mathrm{r})+\mathrm{qgm}(\mathrm{i}, \mathrm{r})]\})$;

VARIABLE (ALL,r,REG)

CON_TAX9y(r)

\# Contribution of TAX COMPONENT 9 to $\mathrm{y}(\mathrm{r}) \#$;

EQUATION E_CON_TAX9y

(ALL,r,REG)

INCOME $(\mathrm{r}) *$ CON_TAX9y $(\mathrm{r})=$ sum(i,TRAD_COMM, $\{$ VDGA(i,r) $*[\operatorname{pgd}(\mathrm{i}, \mathrm{r})+\operatorname{qgd}(\mathrm{i}, \mathrm{r})]\}$

$-\{\operatorname{VDGM}(\mathrm{i}, \mathrm{r}) *[\mathrm{pm}(\mathrm{i}, \mathrm{r})+\operatorname{qgd}(\mathrm{i}, \mathrm{r})]\})$;

VARIABLE (ALL,r,REG) CON_TAX10y(r)

\# Contribution of TAX COMPONENT 10 to $\mathrm{y}(\mathrm{r}) \#$;

EQUATION E_CONT_TAX10y

(ALL,r,REG)

INCOME $(\mathrm{r}) *$ CON_TAX10y $(\mathrm{r})=$ sum(i,TRAD_COMM,sum(s,REG, $\{$ VXWD(i,r,s)*[pfob(i,r,s)+ qxs(i,r,s)]\} $-\{\operatorname{VXMD}(\mathrm{i}, \mathrm{r}, \mathrm{s}) *[\mathrm{pm}(\mathrm{i}, \mathrm{r})+\mathrm{qXs}(\mathrm{i}, \mathrm{r}, \mathrm{s})]\}))$;

VARIABLE (ALL,r,REG)

CON_TAX11y(r)

\# Contribution of TAX COMPONENT 11 to $\mathrm{y}(\mathrm{r}) \#$;

EQUATION E_CON_TAX11y

(ALL,r,REG)

INCOME $(r) *$ CON_TAX11y $(r)=$

sum(i,TRAD_COMM,sum(s,REG, \{VIMS(i,s,r)*[pms(i,s,r)+qxs(i,s,r)]\}

$-\{\operatorname{VIWS}(\mathrm{i}, \mathrm{s}, \mathrm{r}) *[\mathrm{pcif}(\mathrm{i}, \mathrm{s}, \mathrm{r})+\mathrm{qxs}(\mathrm{i}, \mathrm{s}, \mathrm{r})]\}))$;

VARIABLE (ALL, r, REG) incdeflator(r)

\# Deflator for Regional Income \#;

EQUATION E_incdeflator

(ALL, r, REG)

INCOME $(r) *$ incdeflator $(r)=\operatorname{PRIVEXP}(r) * \operatorname{ppriv}(\mathrm{r})+\mathrm{GOVEXP}(\mathrm{r}) * \operatorname{pgov}(\mathrm{r})$ + SAVE $(\mathrm{r}) *$ psave;

VARIABLE (ALL,r,REG) $\operatorname{yg}(r)$

\# Regional Nominal Government Household Expenditure\#;

EQUATION E_yg

!This Equation computes Govt.HH expenditure as Regional HH income less Saving less PRIVEXP ! 
(ALL, r, REG)

GOVEXP(r)*yg(r)=INCOME(r)*y(r)-SAVE $(r) *[p s a v e+q s a v e(r)]$ $-\operatorname{sum}(i$, TRAD_COMM,VPA(i,r)*[pp(i,r)+qp(i,r)]);

VARIABLE

CHK_globalcgds

\# Check Variable for ensuring Global CGDS supply for NETT investment\#;

EQUATION E_CHK_globalcgds

!This equation checks percentage changes in Supply in the omitted market !

CHK_globalcgds=Sum(r,REG,(SH_SAVGLBINV(r)*qsave(r)));

VARIABLE (ALL,r,REG) nom_grinv(r)

\# Regional Nominal GROSS Investment--percentage changes \#;

EQUATION E_nom_grinv

!This equation defines/computes gross nominal investment as sum of qcgds(r) and pcgds(r)!

(All,r, REG)

nom_grinv $(r)=q c g d s(r)+p c g d s(r)$;

VARIABLE (ALL,r,REG) nom_netinv(r)

\# Regional Nominal NET Investment--percentage changes \#;

EQUATION E_nom_netinv

!This equation defines/computes net nominal investment deriving the percentage change form of LEVEL relationship NETINV(r)=REGINV(r)$\operatorname{VDEP}(r)$ !

(All,r, REG)

$\operatorname{NETINV}(\mathrm{r}) *$ nom_netinv $(\mathrm{r})=\operatorname{REGINV}(\mathrm{r}) *$ nom_grinv $(\mathrm{r})-$

$\operatorname{VDEP}(\mathrm{r}) *[\operatorname{pcgds}(\overline{\mathrm{r}})+\mathrm{kb}(\mathrm{r})]$

VARIABLE (ALL,r,REG) qnetinv(r)

\# REAL Regional NET Investment--percentage changes \#;

EQUATION E_qnetinv

!This equation defines/computes net real investment as the difference between Nominal net investment and pcgds(r).!

(All,r, REG)

qnetinv $(r)=$ nom_netinv $(r)-\operatorname{pcgds}(r)$;

\section{A.3 Additional Parameters:}

The additional parameters in the original TABLO file are

COEFFICIENT (all, s, REG_NOT_SRC) HK (s)

!The Destination-specific Human Capital Index parameter!

COEFFICIENT (all, r, SRC) (all, s, REG_NOT_SRC) SS (r,s)

!The Binary Structural similarity Index parameter in the Spillover function!

The values of these parameters are chosen arbitrarily in the parameter file viz., AGPAR1X3.DAT for this aggregation. 


\section{A.4 Additional Coefficients:}

The following boxes show the additional coefficients encoded in TABLO language.

Box 1

COEFFICIENT (all,i,TRAD_COMM) (all,r,SRC) (all,s,REG_NOT_SRC) EMBINDEX(i,r,s)

!The Embodiment Index of Bilateral Technology Flows via Trade!; FORMULA

(all,i, TRAD_COMM) (all,r,SRC) (all,s,REG_NOT_SRC)

EMBINDEX $(\mathrm{i}, \mathrm{r}, \mathrm{s})=\mathrm{VXWD}(\mathrm{i}, \mathrm{r}, \mathrm{s}) / \mathrm{VOW}(\mathrm{i}, \mathrm{s})$;

COEFFICIENT (all,i,TRAD_COMM) (all, r, SRC) (all,s,REG_NOT_SRC) SPLCOEFFT(i,r,s)

!The Value of Spillover Coefficient of Source vis-a-vis Destinations !;

FORMULA

(all,i,TRAD_COMM) (all,r, SRC) (all,s,REG_NOT_SRC)

$\operatorname{SPLCOEFFT}(\mathrm{i}, \mathrm{r}, \mathrm{s})=(\operatorname{EMBINDEX}(\mathrm{i}, \mathrm{r}, \mathrm{s}))^{\wedge}(1-\mathrm{HK}(\mathrm{s}) * \mathrm{SS}(\mathrm{r}, \mathrm{s}))$;

Box 2

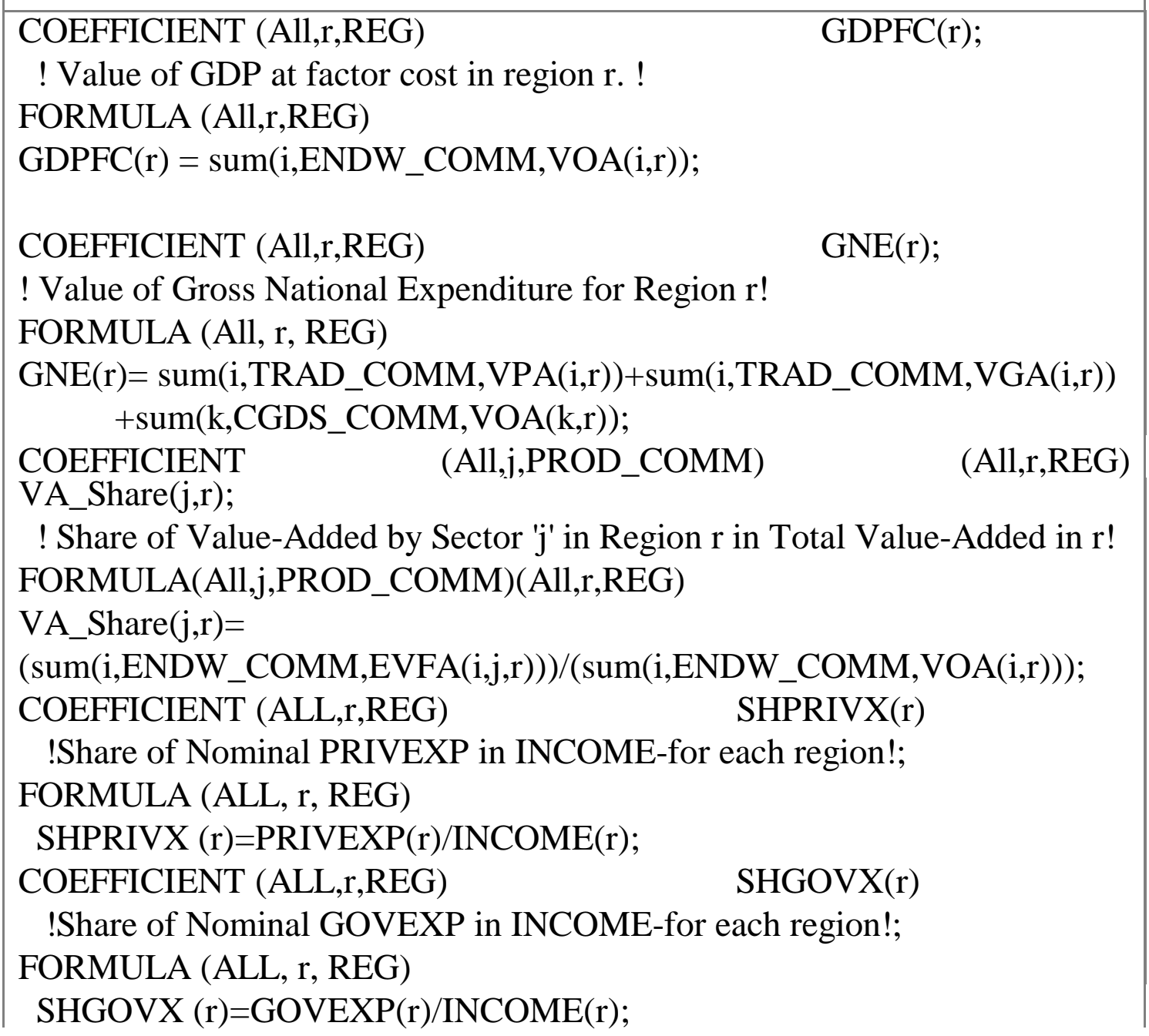


!Share of Nominal net SAVE in INCOME-for each region!;

FORMULA (ALL, r, REG)

SHSAVE $(\mathrm{r})=\mathrm{SAVE}(\mathrm{r}) / \mathrm{INCOME}(\mathrm{r})$;

COEFFICIENT (All,r,REG)

SH_SAVGLBINV(r)

!Share of Nominal net SAVE in GLOBINV-for each region!;

FORMULA (All, r, REG)

SH_SAVGLBINV(r)=SAVE(r)/GLOBINV; COEFFICIENT WORLDVKB

\# Aggregate over Beginning-of-period Capital Stock of all Regions\#; FORMULA WORLDVKB=Sum(r, REG, VKB(r)); COEFFICIENT (All,r,REG) SH_REGVKB(r)

!Share of Regional VKB in GLOBAL VKB as a whole!; FORMULA (All, r, REG) SH_REGVKB(r)=VKB(r)/WORLDVKB;

\section{COEFFICIENT (All,r,REG) \\ CONV_RATIO(r)}

!It is the conversion ratio from NET to GROSS investment-- not the same as GRNETRATIO (r)!;

CONV_RATIO $(r)=N E T I N V(r) / R E G I N V(r)$;

The first one in Box 1 corresponds to Equation (2.4) and the second one to Equation (2.7a) as documented in section 2 in the text. They have three subscripts corresponding to $i \in$ TRAD_COMM, $r \in S R C, s \in R E G \_N O T \_S R C$. $\operatorname{VXWD}(\mathrm{i}, \mathrm{r}, \mathrm{s})$ is the value of exports of traded commodity $\mathrm{i}$ from $\mathrm{r}$ to $\mathrm{s}$ evaluated at world prices. $\operatorname{VOW}(i, s)$ is the value of output in $s$ evaluated at world prices, too. Ratio of these two gives the index for embodied technology spillovers from $r$ to $s$ via trade $\left(E_{r s}\right)$. SPLCOEFFT measures the value of actual spillovers to recipients $\mathrm{s}\left[\gamma_{\mathrm{s}}\left(\mathrm{E}_{\mathrm{rs}}, \theta_{\mathrm{s}}\right)\right]$ depending on the values of $\mathrm{HK}(\mathrm{s})$ and $\mathrm{SS}(\mathrm{r}, \mathrm{s})$.

The first two coefficients in Box 2 are appended in the existing national accounts reporting module for sake of facilitating the computations of some macroeconomic variables. These two define the gross national expenditure (GNE) and GDP at factor cost for each region. The third one defines the share of each value-adding sector (in our case, it is Stuff) in the region wise aggregate value-added. This has been added to capture the effect of value-added augmenting technical change in a particular sector on its share in value-added. In other words, the product of this share and the magnitude of value-added augmenting technical progress yields the region-wide technical change variable [Tec_Chg(r)]. The coefficients SHPRIVX, SHGOVX, and SHSAVE calculate the shares of each categories of income-use in regional nominal income. All these coefficients are added for computational conveniences.

\section{A.5 Encoded Computer Model and Software}

The economic theory underlying the GTAP model is encoded in TABLO language based on FORTRAN programme. The model that we have used for 
the experiment is in TABLO input file named GTAP94.TAB. The model is solved using the TABLO facility of the GEMPACK software developed in MONASH [see Harrison and Pearson (1996)]. The system of linearised equation was solved using the Windows version of GEMPACK software [WINGEM Version 1.5, August 1997]. Harwell sparse matrix code (Duff, 1997) is essential in any TABLO implementation. GTAP solutions are obtained using the 2-4-6 GRAGG method, mid-point solution procedure with extrapolation accuracy.

\section{A.6 Generating Aggregated Data Base}

The INPUT files created for running the data aggregation programme DAGG, in conformity with the three steps described in the text are as follows:

A.6.1 MAP1X3.TXT: the Text file containing the Mapping Vector (written in either ROW, or COLUMN order) for three Commodities to one Stuff. This has been used to create the SUPPLEMENTARY file "SUP1X3.HAR" by MODHAR (running interactively). This HAR file describing the integer mapping vector is used along with the Original DAT2-01.HAR file for $3 \times 3$ GTAP to create in the first stage of DAGG run a file named 1x3GDAT.HAR. This '.HAR' file contained partial aggregation. The file DAGG.INP contains all the input commands for this first run. The text file is produced below:

! This Text File is used to create the SUP file "MAP1x3.HAR" used by DAGG in the Aggregation of GTAP3x3 to 1 sector called Stuff ( MACRO MODEL)!

!Following Mapping Vector is size 3 in column order to the header array "smap"(longname, Stuff mapping) of MAP1x3.HAR.!

31 integer col_order

HEADER "smap" LONGNAME "TRAD_COMM MAPPING";

111

! Next is "PROD_COMM" Mapping And Includes "CGDS" as Non-Traded good!

41 integer col_order

HEADER "cmap" LONGNAME "PROD_COMM MAPPING";

1112

A.6.2 DAGG.INP Files: this is used in the initial run of DAGG using the command - DAGG $\langle D A G G . I N P>D A G G . L O G$. This produces a LOG file containing the information on whether the implementation is 'correct'. 'SMAP' and 'CMAP' in the file DAGG.INP refers to the HEADERS corresponding to Stuff (Trad_Comm) and PROD_COMM mappings. In the second run, another DAGG2.INP file is written for performing the task of complete aggregation for our purpose. This takes as input the HAR file created in the first run (1x3GDAT.HAR) to create the aggregated database in AGGRN1X3.HAR corresponding to the mapping vector in SUP1X3.HAR file. The command used for the second run is the same as the earlier one. Such files are given below: 
DAGG.INP

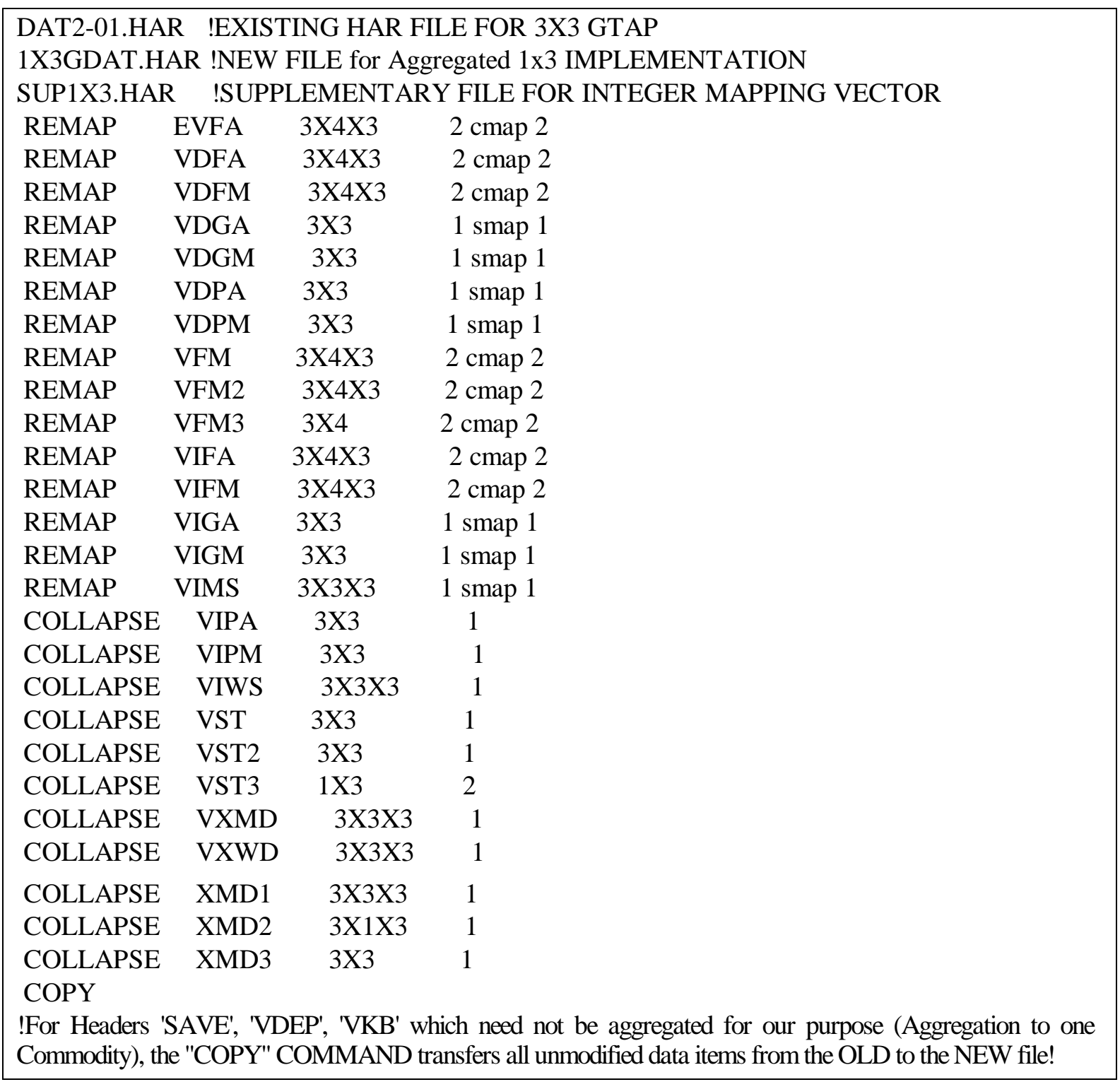

\section{DAGG2.INP}

1X3GDAT.HAR !HAR file for 1st round aggregation using DAGG.INP and input in $2^{\text {nd }}$ round AGGRN1X3.HAR !output file with complete aggregation of GTAP33 to GTAP1x3

SUP1X3.HAR !supplement. file-unused in this round, but used in 1st round

COLLAPSE VDFA 3X2X3 1

COLLAPSE VDFM $3 \times 2 \times 31$

COLLAPSE VIFA $3 \times 2 \times 31$

COLLAPSE VIFM $3 \mathrm{X} 2 \mathrm{X} 31$

COPY

! For Other 'HEADERS' Which Need Not Be Aggregated/Changed in the Second Round, 'Copy' command will transfer them UNMODIFIED in the 'new' Complete Aggregated file AGGRN1X3.HAR !

\section{A.7 List of GTAP variables for current implementation}

The list of GTAP variables including those appended are provided below. 
TABLE A.7 List of GTAP Variables in this implementation ${ }^{\Xi}$

\begin{tabular}{|c|c|c|}
\hline Variables & Set Range & Description \\
\hline qo(i,r) & $\begin{array}{c}\mathrm{i} \in \mathrm{NSAV} \text {.COMM } \\
\mathrm{r} \in \mathrm{REG}\end{array}$ & industry output of commodity $i$ in region $r$ \\
\hline qoes $(\mathrm{i}, \mathrm{j}, \mathrm{r})$ & $\begin{array}{c}\mathrm{i} \in \text { ENDWS_COMM } \\
\mathrm{j} \in \mathrm{PROD} \text {.COMM } \\
\mathrm{r} \in \mathrm{REG}\end{array}$ & supply of sluggish endowment $\mathrm{i}$ used in $\mathrm{j}$, in $\mathrm{r}$ \\
\hline $\operatorname{qxs}(\mathrm{i}, \mathrm{r}, \mathrm{s})$ & $\begin{array}{c}\mathrm{i} \in \mathrm{TRAD} \_\mathrm{COMM} \\
\mathrm{r} \in \mathrm{REG} \quad \mathrm{s} \in \mathrm{REG}\end{array}$ & export sales of commodity $\mathrm{i}$ from $\mathrm{r}$ to region $\mathrm{s}$ \\
\hline qst $(i, r)$ & $\begin{array}{c}\mathrm{i} \in \mathrm{TRAD} \text {.COMM } \\
\mathrm{r} \in \mathrm{REG}\end{array}$ & sales of $\mathrm{i}$ from $\mathrm{r}$ to international transport \\
\hline $\mathrm{qds}(\mathrm{i}, \mathrm{r})$ & $\begin{array}{c}\mathrm{i} \in \mathrm{TRAD} \text {.COMM } \\
\mathrm{r} \in \mathrm{REG}\end{array}$ & domestic sales of commodity $i$ in $r$ \\
\hline qfe $(\mathrm{i}, \mathrm{j}, \mathrm{r})$ & $\begin{array}{c}\mathrm{i} \in \mathrm{ENDW} \text {.COMM } \\
\mathrm{j} \in \mathrm{PROD} \text {.COMM } \\
\mathrm{r} \in \mathrm{REG}\end{array}$ & demand for endowment $\mathrm{i}$ for use in $\mathrm{j}$ in region $\mathrm{r}$ \\
\hline qva(j,r) & $\begin{array}{c}\mathrm{j} \in \mathrm{PROD} \_\mathrm{COMM} \\
\mathrm{r} \in \mathrm{REG}\end{array}$ & value-added in industry $\mathrm{j}$ of region $\mathrm{r}$ \\
\hline qf(i,j,r) & $\begin{array}{c}\mathrm{i} \in \mathrm{TRAD} \_\mathrm{COMM} \\
\mathrm{j} \in \mathrm{PROD} \_\mathrm{COMM} \\
\mathrm{r} \in \mathrm{REG}\end{array}$ & demand for commodity $i$ for use in $\mathrm{j}$ in region $\mathrm{r}$ \\
\hline $\mathrm{qfm}(\mathrm{i}, \mathrm{j}, \mathrm{s})$ & $\begin{array}{c}\mathrm{i} \in \mathrm{TRAD} \text { TCOMM } \\
\mathrm{j} \in \mathrm{PROD} \text {.COMM } \\
\mathrm{s} \in \mathrm{REG}\end{array}$ & Industry demands for aggregate imports \\
\hline qfd(i,j,s) & $\begin{array}{c}\mathrm{i} \in \mathrm{TRAD} \text {.COMM } \\
\mathrm{j} \in \mathrm{PROD} \text {.COMM } \\
\mathrm{s} \in \mathrm{REG}\end{array}$ & Industry demands for domestic goods \\
\hline$q p(\mathrm{i}, \mathrm{r})$ & $\begin{array}{c}\mathrm{i} \in \mathrm{TRAD} \text {.COMM } \\
\mathrm{r} \in \mathrm{REG}\end{array}$ & private household demand for commodity $i$ in region $r$ \\
\hline qg(i,r) & $\begin{array}{c}\mathrm{i} \in \mathrm{TRAD} \text {.COMM } \\
\mathrm{r} \in \mathrm{REG}\end{array}$ & government household demand for commodity $i$ in region $r$ \\
\hline qpm $(\mathrm{i}, \mathrm{s})$ & $\begin{array}{c}\mathrm{i} \in \mathrm{TRAD} \text {.COMM } \\
\mathrm{s} \in \mathrm{REG}\end{array}$ & private hhld demand for imports of $\mathrm{i}$ in region $\mathrm{s}$ \\
\hline qpd(i,s) & $\begin{array}{c}\mathrm{i} \in \mathrm{TRAD} \text {.COMM } \\
\mathrm{s} \in \mathrm{REG}\end{array}$ & private hhld demand for domestic $\mathrm{i}$ in region $\mathrm{s}$ \\
\hline $\operatorname{qgm}(\mathrm{i}, \mathrm{s})$ & $\begin{array}{c}\mathrm{i} \in \mathrm{TRAD} \text {.COMM } \\
\mathrm{s} \in \mathrm{REG}\end{array}$ & government hhld demand for imports of $\mathrm{i}$ in region $\mathrm{s}$ \\
\hline $\operatorname{qgd}(\mathrm{i}, \mathrm{s})$ & $\begin{array}{c}\mathrm{i} \in \mathrm{TRAD} \text {.COMM } \\
\mathrm{s} \in \mathrm{REG}\end{array}$ & government hhld demand for domestic $\mathrm{i}$ in region $\mathrm{s}$ \\
\hline $\operatorname{ksvces}(\mathrm{r})$ & $\mathrm{r} \in \mathrm{REG}$ & capital services = qo("capital",r) \\
\hline qcgds(r) & $\mathrm{r} \in \mathrm{REG}$ & Output of capital goods sector = qo("cgds",r) \\
\hline
\end{tabular}




\begin{tabular}{|c|c|c|}
\hline qsave(r) & $\mathrm{r} \in \mathrm{REG}$ & regional demand for NETT savings \\
\hline $\operatorname{qim}(\mathrm{i}, \mathrm{s})$ & $\underset{\substack{\mathrm{i} \in \mathrm{TRAD} \in \mathrm{REG} \\
\mathrm{s}}}{\mathrm{R} \text { COMM }}$ & aggregate imports of $\mathrm{i}$ in region $\mathrm{s}$ \\
\hline $\operatorname{qiw}(\mathrm{i}, \mathrm{s})$ & 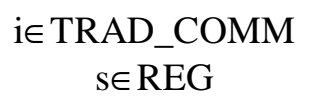 & aggregate imports of $i$ in region $s$, cif weights \\
\hline $\mathrm{qXw}(\mathrm{i}, \mathrm{r})$ & $\underset{r \in \mathrm{REG}}{\mathrm{i} \in \mathrm{TRAD} \text {.COMM }}$ & aggregate exports of $i$ from region $r$, fob weights \\
\hline qxwreg(r) & $\mathrm{r} \in \mathrm{REG}$ & volume of merchandise exports, by region \\
\hline qiwreg(r) & $r \in R E G$ & volume of merchandise imports, by region \\
\hline qxwcom(i) & $\mathrm{i} \in \mathrm{TRAD} \_\mathrm{COMM}$ & volume of global merchandise exports by commodity \\
\hline qiwcom(i) & $\mathrm{i} \in \mathrm{TRAD} \_\mathrm{COMM}$ & volume of global merchandise imports by commodity \\
\hline qxwwld & & volume of world trade \\
\hline qow(i) & $\mathrm{i} \in \mathrm{TRAD} \_\mathrm{COMM}$ & Quantity Index for world supply of good i \\
\hline $\mathrm{kb}(\mathrm{r})$ & $\mathrm{r} \in \mathrm{REG}$ & Beginning-of-period capital stock, in $r$ \\
\hline $\operatorname{ke}(\mathrm{r})$ & $\mathrm{r} \in \mathrm{REG}$ & End-of-period capital stock, in $\mathrm{r}$ \\
\hline globalcgds & & Global supply of capital goods for NET investment \\
\hline $\mathrm{qt}$ & & quantity of global shipping services provided \\
\hline $\operatorname{pop}(\mathrm{r})$ & $\mathrm{r} \in \mathrm{REG}$ & regional population \\
\hline walras_dem & & demand in the omitted market--global demand for savings \\
\hline walras_sup & & supply in omitted market--global supply of cgds composite \\
\hline qgdp(r) & $\mathrm{r} \in \mathrm{REG}$ & GDP quantity index \\
\hline $\mathrm{ps}(\mathrm{i}, \mathrm{r})$ & $\underset{r \in \mathrm{REG}}{\mathrm{i} \in \mathrm{NSAV} \text {.COMM }}$ & supply price of commodity $i$ in region $r$ \\
\hline $\operatorname{pf}(\mathrm{i}, \mathrm{j}, \mathrm{r})$ & $\begin{array}{c}\mathrm{i} \in \mathrm{TRAD} \text { _COMM } \\
\mathrm{j} \in \mathrm{PROD} \text { _COMM } \\
\mathrm{r} \in \mathrm{REG}\end{array}$ & firms' price for commodity $i$ for use in $j$, in $r$ \\
\hline pfe(i,j,r) & $\begin{array}{c}\mathrm{i} \in \mathrm{ENDW} \text {.COMM } \\
\mathrm{j} \in \mathrm{PROD} \text { _COMM } \\
\mathrm{r} \in \mathrm{REG}\end{array}$ & firms' price for endowment commodity $i$ in $j$ of $r$ \\
\hline $\operatorname{pva}(\mathrm{j}, \mathrm{r})$ & $\begin{array}{c}\mathrm{j} \in \mathrm{PROD} \_\mathrm{POMM} \\
\mathrm{r} \in \mathrm{REG}\end{array}$ & firms' price of value-added in industry $j$ of region $r$ \\
\hline $\operatorname{pfm}(\mathrm{i}, \mathrm{j}, \mathrm{s})$ & $\begin{array}{c}\mathrm{i} \in \mathrm{TRAD} \text { _COMM } \\
\mathrm{j} \in \mathrm{PROD} \text { _COMM } \\
\mathrm{s} \in \mathrm{REG} \\
\end{array}$ & price index for imports of $\mathrm{i}$ by $\mathrm{j}$ in region $\mathrm{s}$ \\
\hline $\operatorname{pfd}(\mathrm{i}, \mathrm{j}, \mathrm{s})$ & $\begin{array}{c}\mathrm{i} \in \mathrm{TRAD} \text { _COMM } \\
\mathrm{j} \in \mathrm{PROD} \text { _COMM } \\
\mathrm{s} \in \mathrm{REG}\end{array}$ & price index for domestic purchases of $i$ by $j$ in region $s$ \\
\hline $\mathrm{pp}(\mathrm{i}, \mathrm{r})$ & 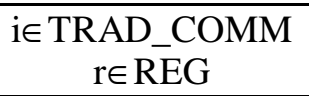 & private household price for commodity $\mathrm{i}$ in region $\mathrm{r}$ \\
\hline $\operatorname{ppm}(\mathrm{i}, \mathrm{s})$ & $\mathrm{i} \in \mathrm{TRAD} \_\mathrm{COMM}$ & price of imports of $\mathrm{i}$ by private households in $\mathrm{s}$ \\
\hline
\end{tabular}




\begin{tabular}{|c|c|c|}
\hline (ppd(i,s) & $\begin{array}{c}\mathrm{i} \in \mathrm{TRAD} \text { TRCOMM } \\
\mathrm{s} \in \mathrm{REG}\end{array}$ & price of domestic i to private households in $\mathrm{s}$ \\
\hline $\operatorname{pgov}(\mathrm{r})$ & $\mathrm{r} \in \mathrm{REG}$ & price index for govt hhld expenditures in region $\mathrm{r}$ \\
\hline ppriv(r) & $\mathrm{r} \in \mathrm{REG}$ & price index for private household expenditures in region $\mathrm{r}$ \\
\hline $\operatorname{pg}(\mathrm{i}, \mathrm{r})$ & $\begin{array}{c}\mathrm{i} \in \mathrm{TRAD} \text { TR_COMM } \\
\mathrm{r} \in \mathrm{REG}\end{array}$ & government household price for commodity $i$ in region $r$ \\
\hline $\operatorname{pgm}(\mathrm{i}, \mathrm{s})$ & $\begin{array}{c}\mathrm{i} \in \mathrm{TRAD} \text { TRCOMM } \\
\mathrm{s} \in \mathrm{REG}\end{array}$ & price of imports of $\mathrm{i}$ by government households in $\mathrm{s}$ \\
\hline $\operatorname{pgd}(\mathrm{i}, \mathrm{s})$ & $\begin{array}{c}\mathrm{i} \in \mathrm{TRAD} \text { TRCOMM, } \\
\mathrm{s} \in \mathrm{REG}\end{array}$ & price of domestic i to government households in $\mathrm{s}$ \\
\hline $\operatorname{pm}(\mathrm{i}, \mathrm{r})$ & 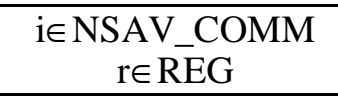 & market price of commodity $i$ in region $r$ \\
\hline $\operatorname{pim}(i, r)$ & $\begin{array}{c}\mathrm{i} \in \mathrm{TRAD} \text { TR_COMM } \\
\mathrm{r} \in \mathrm{REG}\end{array}$ & market price of composite import $\mathrm{i}$ in region $\mathrm{r}$ \\
\hline $\operatorname{piw}(\mathrm{i}, \mathrm{r})$ & $\begin{array}{c}\mathrm{i} \in \mathrm{TRAD} \text { TR_COMM } \\
\mathrm{r} \in \mathrm{REG}\end{array}$ & world price of composite import $i$ in region $r$ \\
\hline $\operatorname{pxw}(\mathrm{i}, \mathrm{r})$ & $\begin{array}{c}\mathrm{i} \in \mathrm{TRAD} \text { TRCOMM } \\
\mathrm{r} \in \mathrm{REG}\end{array}$ & aggregate exports price index of $i$ from region $r$ \\
\hline pxwreg(r) & $\mathrm{r} \in \mathrm{REG}$ & price index of merchandise exports, by region \\
\hline piwreg(r) & $\mathrm{r} \in \mathrm{REG}$ & price index of merchandise imports, by region \\
\hline pxwcom(i) & $\mathrm{i} \in \mathrm{TRAD} \_$COMM & price index of global merchandise exports by commodity \\
\hline piwcom(i) & $\mathrm{i} \in \mathrm{TRAD} \_$COMM & price index of global merchandise imports by commodity \\
\hline pxwwld & - & price index of world trade \\
\hline pw(i) & $\mathrm{i} \in \mathrm{TRAD} \_$COMM & World price index for total good i supplies \\
\hline pmes(i,j,r) & $\begin{array}{c}\mathrm{i} \in \text { ENDWS_COMM } \\
\mathrm{j} \in \mathrm{PROD} \text { PROMM } \\
\mathrm{r} \in \mathrm{REG}\end{array}$ & market price of sluggish endowment used by $\mathrm{j}$, in $\mathrm{r}$ \\
\hline $\operatorname{pms}(\mathrm{i}, \mathrm{r}, \mathrm{s})$ & $\begin{array}{c}\mathrm{i} \in \mathrm{TRAD} \text { TCOMM } \\
\mathrm{r} \in \mathrm{REG} \mathrm{s} \in \mathrm{REG}\end{array}$ & domestic price for good i supplied from $\mathrm{r}$ to region $\mathrm{s}$ \\
\hline pfob(i,r,s) & $\begin{array}{c}\mathrm{i} \in \mathrm{TRAD} \text { COMM } \\
\mathrm{r} \in \mathrm{REG} \mathrm{s} \in \mathrm{REG}\end{array}$ & FOB world price of commodity i supplied from $r$ to $s$ \\
\hline pcif(i,r,s) & $\begin{array}{c}\mathrm{i} \in \mathrm{TRAD} \text { _COMM } \\
\mathrm{r} \in \mathrm{REG} \mathrm{s} \in \mathrm{REG}\end{array}$ & CIF world price of commodity i supplied from $r$ to $s$ \\
\hline $\mathrm{pt}$ & & price of global shipping services provided \\
\hline rental(r) & $\mathrm{r} \in \mathrm{REG}$ & rental rate on capital = ps("capital",r) \\
\hline $\operatorname{rorc}(\mathrm{r})$ & $\mathrm{r} \in \mathrm{REG}$ & Current net rate of return on capital stock, in $\mathrm{r}$ \\
\hline rore $(\mathrm{r})$ & $\mathrm{r} \in \mathrm{REG}$ & Expected net rate of return on capital stock, in $\mathrm{r}$ \\
\hline rorg & - & Global net rate of return on capital stock \\
\hline psave & - & price of capital goods supplied to savers \\
\hline $\operatorname{pcgds}(\mathrm{r})$ & $\mathrm{r} \in \mathrm{REG}$ & price of investment goods = ps("cgds",r) \\
\hline $\mathrm{psw}(\mathrm{r})$ & $\mathrm{r} \in \mathrm{REG}$ & Index of prices received for tradeables produced in $\mathrm{r}$ \\
\hline $\mathrm{pdw}(\mathrm{r})$ & $\mathrm{r} \in \mathrm{REG}$ & Index of prices paid for tradeables used in region $\mathrm{r}$ \\
\hline $\operatorname{tot}(\mathrm{r})$ & $\mathrm{r} \in \mathrm{REG}$ & terms of trade for region $r$ : tot $(r)=p s w(r)-p d w(r)$ \\
\hline $\operatorname{pr}(\mathrm{i}, \mathrm{r})$ & $\begin{array}{c}\mathrm{i} \in \mathrm{TRAD} \text { R_COMM } \\
\mathrm{r} \in \mathrm{REG}\end{array}$ & ratio of domestic to imported prices in $r$ \\
\hline $\operatorname{pgdp}(\mathrm{r})$ & $\mathrm{r} \in \mathrm{REG}$ & GDP price index \\
\hline $\mathrm{ao}(\mathrm{j}, \mathrm{r})$ & $\begin{array}{c}\mathrm{j} \in \text { PROD_COMM } \\
\mathrm{r} \in \mathrm{REG}\end{array}$ & output augmenting technical change in sector $\mathrm{j}$ of $\mathrm{r}$ \\
\hline afe $(\mathrm{i}, \mathrm{j}, \mathrm{r})$ & $\begin{array}{c}\mathrm{i} \in \mathrm{ENDW} \mathrm{eNCOMM} \\
\mathrm{j} \in \mathrm{PROD} \text { _COMM } \\
\mathrm{r} \in \mathrm{REG}\end{array}$ & primary factor $\mathrm{i}$ augmenting tech change in $\mathrm{j}$ of $\mathrm{r}$ \\
\hline
\end{tabular}




\begin{tabular}{|c|c|c|}
\hline $\operatorname{af}(\mathrm{i}, \mathrm{j}, \mathrm{r})$ & $\begin{array}{c}\mathrm{i} \in \mathrm{TRAD} \text { TRCOMM } \\
\mathrm{j} \in \mathrm{PROD} \text { PROMM } \\
\mathrm{r} \in \mathrm{REG}\end{array}$ & composite interm. input $i$ augmenting tech change in $j$ of $r$ \\
\hline ava(i,r) & $\underset{r \in \text { REG }}{\mathrm{i} \in \text { PROD_COMM }}$ & Value added augmenting tech change in sector $i$ of $r$ \\
\hline $\operatorname{atr}(\mathrm{i}, \mathrm{r}, \mathrm{s})$ & $\begin{array}{l}\mathrm{i} \in \text { TRAD_COMM } \\
\mathrm{r} \in \text { REG } \mathrm{s} \in \mathrm{REG}\end{array}$ & tech change parameter in shipping of $i$ from region $r$ to $s$ \\
\hline to(i,r) & $\begin{array}{l}\mathrm{i} \in \mathrm{NSAV} \text { NCOMM } \\
\mathrm{r} \in \mathrm{REG}\end{array}$ & output (or income) tax in region $r$ \\
\hline $\operatorname{tf}(\mathrm{i}, \mathrm{j}, \mathrm{r})$ & $\begin{array}{c}\mathrm{i} \in \mathrm{ENDW} \text { ENCOMM } \\
\mathrm{j} \in \mathrm{PROD} \text { PCOMM } \\
\mathrm{r} \in \mathrm{REG}\end{array}$ & tax on primary factor $\mathrm{i}$ used by $\mathrm{j}$ in region $\mathrm{r}$ \\
\hline tpm(i,r) & $\begin{array}{c}\mathrm{i} \in \text { TRAD_COMM } \\
\mathrm{r} \in \mathrm{REG}\end{array}$ & tax on imported i purchased by private hhlds in $\mathrm{r}$ \\
\hline $\operatorname{tpd}(\mathrm{i}, \mathrm{r})$ & $\begin{array}{l}\mathrm{i} \in \mathrm{TRAD} \text { TRCOMM } \\
\mathrm{r} \in \mathrm{REG}\end{array}$ & tax on domestic i purchased by private hhld in $\mathrm{r}$ \\
\hline $\operatorname{tgm}(i, r)$ & $\begin{array}{c}\mathrm{i} \in \text { TRAD_COMM } \\
\mathrm{r} \in \mathrm{REG}\end{array}$ & tax on imported i purchased by gov't hhld in $r$ \\
\hline $\operatorname{tgd}(\mathrm{i}, \mathrm{r})$ & $\begin{array}{l}\mathrm{i} \in \text { TRAD_COMM } \\
\mathrm{r} \in \mathrm{REG}\end{array}$ & tax on domestic i purchased by government hhlds in $\mathrm{r}$ \\
\hline $\operatorname{tfm}(\mathrm{i}, \mathrm{j}, \mathrm{r})$ & $\begin{array}{c}\mathrm{i} \in \mathrm{TRAD} \mathrm{TR} \in \mathrm{PROD} C \mathrm{COMM} \\
\mathrm{r} \in \mathrm{REG}\end{array}$ & tax on imported i purchased by $\mathrm{j}$ in $\mathrm{r}$ \\
\hline $\operatorname{tfd}(\mathrm{i}, \mathrm{j}, \mathrm{r})$ & $\begin{array}{c}\mathrm{i} \in \mathrm{TRAD} \text { ACOMM } \\
\mathrm{j} \in \mathrm{PROD} \text { PCOMM } \\
\mathrm{r} \in \mathrm{REG}\end{array}$ & tax on domestic i purchased by $\mathrm{j}$ in $\mathrm{r}$ \\
\hline $\operatorname{txs}(\mathrm{i}, \mathrm{r}, \mathrm{s})$ & $\begin{array}{l}\mathrm{i} \in \text { TRAD_COMM } \\
\mathrm{r} \in \mathrm{REG} \mathrm{s} \in \mathrm{REG}\end{array}$ & combined tax in $\mathrm{r}$ on good $\mathrm{i}$ bound for region $\mathrm{s}$ \\
\hline $\operatorname{tms}(\mathrm{i}, \mathrm{r}, \mathrm{s})$ & $\begin{array}{c}\mathrm{i} \in \mathrm{TRAD} \text { TROMM } \\
\mathrm{r} \in \mathrm{REG} \mathrm{s} \in \mathrm{REG}\end{array}$ & import tax in $\mathrm{s}$ on good $\mathrm{i}$ imported from region $\mathrm{r}$ \\
\hline $\operatorname{tm}(\mathrm{i}, \mathrm{s})$ & $\underset{\substack{\mathrm{i} \in \mathrm{TRAD} \text { TREG } \\
\text { REMM }}}{\mathrm{RE}}$ & variable import levy -- source generic \\
\hline $\operatorname{tx}(\mathrm{i}, \mathrm{r})$ & $\begin{array}{c}\mathrm{i} \in \text { TRAD_COMM } \\
\mathrm{r} \in \mathrm{REG}\end{array}$ & variable export tax (subsidy) -- destination generic \\
\hline vxwreg(r) & $\mathrm{r} \in \mathrm{REG}$ & value of merchandise exports, by region \\
\hline viwreg(r) & $\mathrm{r} \in \mathrm{REG}$ & value of merchandise imports, by region, at world prices \\
\hline viwcif(i,s) & $\begin{array}{c}\mathrm{i} \in \mathrm{TRAD} \text { TRCOMM } \\
\mathrm{s} \in \mathrm{REG}\end{array}$ & value of merchandise regional imports, by commodity, cif \\
\hline vxwfob(i,s) & $\begin{array}{c}\mathrm{i} \in \mathrm{TRAD} \text { TROCMM } \\
\mathrm{s} \in \mathrm{REG} \\
\end{array}$ & value of merchandise regional exports, by commodity, fob \\
\hline vxwcom(i) & $\mathrm{i} \in \mathrm{TRAD} \_\mathrm{COMM}$ & value of global merchandise exports by commodity \\
\hline viwcom(i) & $\mathrm{i} \in \mathrm{TRAD} \_$COMM & $\begin{array}{l}\text { value of global merchandise imports by commodity, at world } \\
\text { prices }\end{array}$ \\
\hline vxwwld & $=$ & value of world trade \\
\hline valuew(i) & $\mathrm{i} \in \mathrm{TRAD} \_\mathrm{COMM}$ & value of world supply of good i \\
\hline $\operatorname{vgdp}(\mathrm{r})$ & $\mathrm{r} \in \mathrm{REG}$ & change in value of GDP \\
\hline $\mathrm{y}(\mathrm{r})$ & $\mathrm{r} \in \mathrm{REG}$ & regional household income, in region $\mathrm{r}$ \\
\hline $\mathrm{yp}(\mathrm{r})$ & $\mathrm{r} \in \mathrm{REG}$ & regional private household expenditure, in region $\mathrm{r}$ \\
\hline $\mathrm{up}(\mathrm{r})$ & $\mathrm{r} \in \mathrm{REG}$ & per capita utility from private expend., in region $r$ \\
\hline $\mathrm{ug}(\mathrm{r})$ & $\mathrm{r} \in \mathrm{REG}$ & per capita utility from gov't expend., in region $r$ \\
\hline
\end{tabular}




\begin{tabular}{|c|c|c|}
\hline $\bar{u} \mathrm{u}(\mathrm{r})$ & $\mathrm{r} \in \mathrm{REG}$ & per capita utility from aggregate hhld expend., in region $r$ \\
\hline $\mathrm{EV}(\mathrm{r})$ & $\mathrm{r} \in \mathrm{REG}$ & Equivalent Variation, \$ US million \\
\hline WEV & _- & Equivalent variation for the world \\
\hline DTBAL(r) & $\mathrm{r} \in \mathrm{REG}$ & Change in trade balance $\Delta(\mathrm{X}-\mathrm{M}), \$$ US million \\
\hline DTBALi(i,r) & $\begin{array}{l}\mathrm{i} \in \mathrm{TRAD} \text { TRCOMM } \\
\mathrm{r} \in \mathrm{REG}\end{array}$ & $\begin{array}{l}\text { Change in trade balance by commodity and by region, } \\
\text { \$US million }\end{array}$ \\
\hline profitslack(j,r) & $\begin{array}{c}\mathrm{j} \in \mathrm{PROD} \text { PRCOMM } \\
\mathrm{r} \in \mathrm{REG}\end{array}$ & slack variable in the zero profit equation \\
\hline incomeslack(r) & $\mathrm{r} \in \mathrm{REG}$ & slack variable in the expression for regional income \\
\hline endwslack(i,r) & $\begin{array}{l}\mathrm{i} \in \mathrm{ENDW}_{\mathrm{E}} \in \mathrm{REG} \\
\mathrm{REM}\end{array}$ & $\begin{array}{l}\text { slack variable in the endowment market clearing } \\
\text { condition }\end{array}$ \\
\hline cgdslack(r) & $\mathrm{r} \in \mathrm{REG}$ & slack variable for qcgds $(\mathrm{r})$ \\
\hline saveslack(r) & $\mathrm{r} \in \mathrm{REG}$ & slack variable in regional demand for savings \\
\hline govslack(r) & $\mathrm{r} \in \mathrm{REG}$ & slack variable to permit fixing of real govt purchases \\
\hline tradslack(i,r) & $\begin{array}{c}\mathrm{i} \in \mathrm{TRAD} \text {.COMM } \\
\mathrm{r} \in \mathrm{REG}\end{array}$ & slack variable in the tradeables market clearing condition \\
\hline walraslack & _- & slack variable in the omitted market \\
\hline world_price(r) & $\mathrm{r} \in \mathrm{REG}$ & regional world price effect \\
\hline export_price(r) & $\mathrm{r} \in \mathrm{REG}$ & regional export price effect \\
\hline exp_price_com(i,r) & $\begin{array}{l}\mathrm{i} \in \mathrm{TRAD} \text {.COMM } \\
\mathrm{r} \in \mathrm{REG}\end{array}$ & commodity-wise export price effect \\
\hline import_price(r) & $\mathrm{r} \in \mathrm{REG}$ & regional import price effect \\
\hline McDougall_TOT(r) & $\mathrm{r} \in \mathrm{REG}$ & conventional terms-of-trade changes \\
\hline NA_realc(r) & $\mathrm{r} \in \mathrm{REG}$ & Real private household consumption by region $r$ \\
\hline NA_reali(r) & $\mathrm{r} \in \mathrm{REG}$ & Real gross investment expenditure by region $\mathrm{r}$ \\
\hline NA_realg(r) & $\mathrm{r} \in \mathrm{REG}$ & Real public consumption by region $r$ \\
\hline NA_realx(r) & $\mathrm{r} \in \mathrm{REG}$ & Real value of exports (fob weights) by region $\mathrm{r}$ \\
\hline NA_realm(r) & $\mathrm{r} \in \mathrm{REG}$ & Real value of imports (cif weights) by region $r$ \\
\hline NA_pric(r) & $\mathrm{r} \in \mathrm{REG}$ & Price index for private household consumption by region $\mathrm{r}$ \\
\hline NA_prii(r) & $\mathrm{r} \in \mathrm{REG}$ & Price index for gross investment expenditure by region $\mathrm{r}$ \\
\hline NA_prig(r) & $\mathrm{r} \in \mathrm{REG}$ & Price index for public consumption by region $\mathrm{r}$ \\
\hline NA_prigne(r) & $\mathrm{r} \in \mathrm{REG}$ & Price index for GNE by region \\
\hline NA_prix(r) & $\mathrm{r} \in \mathrm{REG}$ & Price index for exports (fob weights) by region \\
\hline NA_prim(r) & $\mathrm{r} \in \mathrm{REG}$ & Price index for imports (cif weights) by region \\
\hline NA_gdpexp(r) & $\mathrm{r} \in \mathrm{REG}$ & Nominal GDP from the expenditure side by region \\
\hline NA_gdpinc(r) & $\mathrm{r} \in \mathrm{REG}$ & $\begin{array}{l}\text { Nominal GDP from income side (at market prices) by } \\
\text { region }\end{array}$ \\
\hline NA_prigdp(r) & $\mathrm{r} \in \mathrm{REG}$ & Price index for GDP (at market prices) by region \\
\hline NA_prigdpin(r) & $\mathrm{r} \in \mathrm{REG}$ & Price index for GDP (from income side) by region \\
\hline NA_prigdpfc(r) & $\mathrm{r} \in \mathrm{REG}$ & Price index for GDP (at factor cost) by region \\
\hline NA_realgdp(r) & $\mathrm{r} \in \mathrm{REG}$ & Real GDP (at market prices) by region \\
\hline NA_realgdpfc(r) & $\mathrm{r} \in \mathrm{REG}$ & Real GDP (at factor cost) by region \\
\hline Del_BTgdp(r) & $\mathrm{r} \in \mathrm{REG}$ & $\begin{array}{l}\text { Change in Balance of Trade as a percentage of } \\
\text { GDP, by region }\end{array}$ \\
\hline tms_ave(i,s) & $\begin{array}{c}\mathrm{i} \in \mathrm{TRAD} \text { TRCOMM } \\
\mathrm{s} \in \mathrm{REG} \\
\end{array}$ & Region-wide values of import-tax powers \\
\hline
\end{tabular}




\begin{tabular}{|c|c|c|}
\hline tms_ave_ave(s) & $\mathrm{s} \in \mathrm{REG}$ & Average import-tax power \\
\hline $\operatorname{pfac}(\mathrm{i}, \mathrm{r})$ & $\begin{array}{l}\mathrm{i} \in \mathrm{ENDW} \text {.COMM } \\
\mathrm{r} \in \mathrm{REG}\end{array}$ & Region-wide prices of endowement commodities \\
\hline Tec_Chg(r) & $\mathrm{r} \in \mathrm{REG}$ & regional technological change shifter \\
\hline NA_gdpfc(r) & $\mathrm{r} \in \mathrm{REG}$ & Value of Nominal GDP at factor cost \\
\hline NA_realgdpinc(r) & $\mathrm{r} \in \mathrm{REG}$ & $\begin{array}{l}\text { Real GDP(at market prices)from Income Side by } \\
\text { region }\end{array}$ \\
\hline NA_gne(r) & $\mathrm{r} \in \mathrm{REG}$ & Value of GNE (at market prices) by region \\
\hline NA_realgne(r) & $\mathrm{r} \in \mathrm{REG}$ & Value of Real Gross National Expenditure \\
\hline CON_PFACy(r) & $\mathrm{r} \in \mathrm{REG}$ & Contribution of primary factor payments to $\mathrm{y}(\mathrm{r})$ \\
\hline CON_DEPy(r) & $\mathrm{r} \in \mathrm{REG}$ & Contribution of Depreciation factor to $\mathrm{y}(\mathrm{r})$ \\
\hline CON_PHYS_DEPy(r) & $\mathrm{r} \in \mathrm{REG}$ & Contribution of Physical Depreciation to $y(r)$ \\
\hline CON_VALUE_DEPy(r) & $\mathrm{r} \in \mathrm{REG}$ & Contribution of revaluation of Capital stock to $\mathrm{y}(\mathrm{r})$ \\
\hline CON_TAX1y(r) & $\mathrm{r} \in \mathrm{REG}$ & Contribution of TAX COMPONENT 1 to $\mathrm{y}(\mathrm{r})$ \\
\hline CON_TAX2y(r) & $\mathrm{r} \in \mathrm{REG}$ & Contribution of TAX COMPONENT 2 to $\mathrm{y}(\mathrm{r})$ \\
\hline CON_TAX3y(r) & $\mathrm{r} \in \mathrm{REG}$ & Contribution of TAX COMPONENT 3 to $\mathrm{y}(\mathrm{r})$ \\
\hline CON_TAX4y(r) & $\mathrm{r} \in \mathrm{REG}$ & Contribution of TAX COMPONENT 4 to $\mathrm{y}(\mathrm{r})$ \\
\hline CON_TAX5y(r) & $\mathrm{r} \in \mathrm{REG}$ & Contribution of TAX COMPONENT 5 to y(r) \\
\hline CON_TAX6y(r) & $\mathrm{r} \in \mathrm{REG}$ & Contribution of TAX COMPONENT 6 to $\mathrm{y}(\mathrm{r})$ \\
\hline CON_TAX7y(r) & $\mathrm{r} \in \mathrm{REG}$ & Contribution of TAX COMPONENT 7 to $\mathrm{y}(\mathrm{r})$ \\
\hline CON_TAX8y(r) & $\mathrm{r} \in \mathrm{REG}$ & Contribution of TAX COMPONENT 8 to y(r) \\
\hline CON_TAX9y(r) & $\mathrm{r} \in \mathrm{REG}$ & Contribution of TAX COMPONENT 9 to $\mathrm{y}(\mathrm{r})$ \\
\hline CON_TAX10y(r) & $\mathrm{r} \in \mathrm{REG}$ & Contribution of TAX COMPONENT 10 to y(r) \\
\hline CON_TAX11y(r) & $\mathrm{r} \in \mathrm{REG}$ & Contribution of TAX COMPONENT 11 to y(r) \\
\hline incdeflator(r) & $\mathrm{r} \in \mathrm{REG}$ & Deflator for Regional Income \\
\hline $\operatorname{yg}(\mathrm{r})$ & $\mathrm{r} \in \mathrm{REG}$ & $\begin{array}{l}\text { Regional nominal government household } \\
\text { expenditure }\end{array}$ \\
\hline CHK_globalcgds & - & $\begin{array}{l}\text { Check variable for ensuring global cgds supply for } \\
\text { nett investment }\end{array}$ \\
\hline nom_grinv(r) & $\mathrm{r} \in \mathrm{REG}$ & \begin{tabular}{|l}
$\begin{array}{l}\text { Regional nominal gross investment--percentage } \\
\text { changes }\end{array}$ \\
\end{tabular} \\
\hline nom_netinv(r) & $\mathrm{r} \in \mathrm{REG}$ & \begin{tabular}{|llll||}
$\begin{array}{l}\text { Regional nominal net investment--percentage } \\
\text { changes }\end{array}$ & . \\
\end{tabular} \\
\hline qnetinv(r) & $\mathrm{r} \in \mathrm{REG}$ & real regional net investment--percentage changes \\
\hline EV_ALT(r) & $\mathrm{r} \in \mathrm{REG}$ & $\begin{array}{l}\text { expression for regional EV computed in alternative } \\
\text { way }\end{array}$ \\
\hline WEV_ALT & & expression for WEV computed in alternative way \\
\hline
\end{tabular}

$\Xi$ The variables in the first column of the Table represent percentage deviations from the basecase of level variables. 